\title{
Futuro de la política de desarrollo rural en Europa. Apectos principales de la normativa para el periodo de programación 2014-2020
}

\author{
Xavier Bolivar LASTRA BRAVO \\ Área de Proyectos de Ingeniería \\ Universidad de Almería \\ xlastra@ual.es \\ Alfredo TOLÓN BECERRA \\ Área de Proyectos de Ingeniería \\ Universidad de Almería \\ atolon@ual.es \\ Miguel Ángel GARCía ArIAS \\ Director Regional para América Central \\ de Acción contra el Hambre (ACF-E)
}

Recibido: 27 de enero de 2014

Enviado a evaluar: 13 de febrero de 2014

Aceptado: 14 de abril de 2014

\section{RESUMEN}

La Política de Desarrollo Rural europea, para el periodo de programación 2014-2020, busca reforzar los avances alcanzados en los anteriores periodos de programación, promover un mayor componente ambiental, al vincular sus objetivos a los de la Estrategia Europa 2020 para un crecimiento inteligente, sostenible e integrador, y una mayor cohesión territorial al vincularlos con otras políticas sectoriales. Sigue apostando por los Grupos de Acción Local como principales gestores de las operaciones y acciones a desarrollar, al mismo tiempo que se busca facilitar sus actividades mediante la financiación coordinada de los distintos fondos europeos relacionados con el desarrollo rural, la simplificación de la carga administrativa, y una mayor cooperación intra e interterritorial. En este nuevo periodo se dará un especial impulso a las medidas en sectores con perspectivas de crecimiento importante, y de carácter innovador, y a las acciones con enfoque integrado, y focalizadas en jóvenes, mujeres y grupos minoritarios.

Palabras clave: Normativa europea de Desarrollo Rural, Fondos EIE, Medidas de desarrollo rural, España. 


\title{
The future of European rural development policy. Main regulatory aspects for the programming period 2014-2020
}

\begin{abstract}
The European Rural Development Policy for the programming period 2014-2020 aims to reinforce the progress made in previous programming periods, to promote greater environmental component by linking the objectives of the Europe 2020 strategy for smart, sustainable and inclusive growth, and greater territorial cohesion by linking with other sectorial policies. Local action groups will still be the main responsible of operations and actions. Facilitating their activities through coordinated funding of the several European funds related to rural development, reduction of administrative burden, and increasing intra and inter-regional cooperation, will be seek out. The measures in sectors with significant growth prospects, and innovative, and actions with integrated approach and focused on youth, women and minority groups, will be mainly promoted too.
\end{abstract}

Key words: European regulation for Rural Development, ESI Funds, rural development measures, Spain.

L'avenir de la polotoque européenne de développment rural. Pricipaux aspects réglementaires pour la période de programmation 2014-2020

\section{RÉSUMÉ}

La politique de développement rural européenne pour la période de programmation 2014-2020, vise à renforcer les progrès réalisés au cours des périodes de programmation précédentes, promouvoir une plus grande importance de l'environnement, due au lien aux objectifs de la stratégie Europe 2020 pour une croissance intelligente, durable et inclusive, et une plus grande cohésion territoriale due au lien a d'autres politiques sectorielles. Elle continue à promouvoir les groupes d'action locaux comme principaux responsables des opérations et des actions à entreprendre, en même temps qu'elle cherche à faciliter la coordination de leurs activités grâce au financement des différents fonds européens liés au développement rural, la simplification de la charge administrative, et le renforcement de la coopération intra et interterritorial. Dans cette nouvelle période, on donnera une impulsion particulière aux mesures dans les secteurs avec les perspectives de croissance importantes, et innovante, et les actions avec une approche intégrée, et axée sur les jeunes, les femmes et les groupes minoritaires.

Mots clés: Réglementation européenne pour le Développement Rural, Fonds ESI, Mesures de développement rural, Espagne.

\section{PRINCIPALES HITOS EN LA EVOLUCIÓN DE LA POLÍTICA DE DESARROLLO RURAL DE LA UNIÓN EUROPEA}

En 1957, se creó la Comunidad Económica Europea (CEE) y la Comunidad de la Energía Atómica (EURATOM) mediante la firma del Tratado de Roma. Este tratado fue firmado por seis países: Francia, Países Bajos, Bélgica, Luxemburgo, Italia y la República Federal de Alemania. A través de este acuerdo se establecieron medidas económicas de carácter general para impulsar una unión aduanera. En el campo agrícola, se establecieron medidas para fomentar el productivismo agrario a través de 
la Política Agraria de precios y mercados, cuyo único objetivo fue regular la producción agrícola.

Al año siguiente, se puso de manifiesto la necesidad de reformar las estructuras agrarias y de conseguir un mayor nivel de competitividad, junto con el mantenimiento de la explotación familiar, como modo de vida rural, en la Conferencia de Stresa. Como resultado, se dio paso al primer proyecto de Política Agraria Común (PAC), que se materializó en 1960 a través de las siguientes medidas: la unidad de mercado, la preferencia comunitaria y la solidaridad financiera. En 1962, la PAC adopta una orientación estrictamente sectorial, dirigida a los agricultores y las empresas agrícolas, y compuesta de dos medidas: sostén de los precios e intervención en los mercados de productos agrícolas, y transformación de las estructuras agrarias (De Pablo et al, 2006; Cazorla, 1994; FAO, 2003).

A partir del año 1988 se otorgó un carácter territorial a la política estructural europea, mediante la reforma de los Fondos Estructurales Comunitarios (FEC) (FAO, 2003). Se estableció como segundo pilar el desarrollo rural, y se establecieron tres Fondos (FEDER, FSE y FEOGA-O), con sus objetivos y normas generales de uso (Figura 1). Estos fondos se rigen por el principio de subsidiariedad, es decir, las decisiones sobre la utilización de los fondos se toman descentralizadamente al nivel más oportuno según cada caso y país (FAO, 2003).

Figura 1. Objetivos y normas de uso de los FEC.

\section{Objetivos de los FEC'}

-Desartolloregional en regiones atrasadas (Regiones Objetivo 1).

- Reconversión de zonas industriales en declive (Zonas Objetivo 2 ).

- Lucha contra el desempleo de larga duración (Objetivo 3).

Convergencia

Normas generales de uso de los FEC

- Acceso al mercado de trabajo de los jóvenes (Objetivo 4).

- Ajuste estructural de la agricultura (Objetivo 5a).

- Desarrollo nural en zonas rurales en declireno situadas en regiones atrasadas (Zonas Objetivo $5 \mathrm{~b}$ ).
- Concentración

- Partenariado

- Programación

- Adicionalidad

- Seguimiento-evaluación

Fuente: Elaboración propia.

La primera reforma en profundidad de las PAC se dio en 1992, cambiando la política de apoyo vía precios por una vía ayudas. Se creó el Fondo de Cohesión para financiar proyectos de ambientales y de infraestructuras en los países de cohesión (PIB per cápita $<90 \%$ de la media comunitaria). Se introdujeron tres medidas de acompañamiento en el objetivo 5a: el fomento de prácticas agrícolas compatibles con 
la conservación del medio ambiente (programas ambientales), la reforestación de tierras agrarias y el cese anticipado de la actividad agraria (FODEPAL, 2006).

A partir de la Declaración de Cork (1996) se da una aplicación práctica a la PAC y se marca el camino a seguir en materia de desarrollo rural, a través de los Reglamentos (CE) No 1257/1999 y Nº 1260/1999. En este último se profundizó las características del desarrollo que se pretendió desarrollar, pero se asumió que este no puede presentar diferencias sustanciales con respecto al desarrollo en general propugnado por la UE (De Pablo et al, 2006). Se estableció que el desarrollo debe ser armonioso, equilibrado y duradero en lo referente a las actividades económicas. Además, se pretendió que las zonas rurales de las distintas regiones se conviertan en lugares más atractivos, económica y socialmente, tanto para la creación de empleo, como la vida humana en general. En este sentido, la Política de desarrollo rural se convirtió en un elemento determinante de la Cohesión Económica y Social, que realiza la triple función: productiva, social y ambiental, del conjunto de las zonas rurales de la UE. El objeto del desarrollo rural debe ser el marco general en el cual tiene lugar la vida humana, por tanto los factores ambientales, culturales y sociales, deben ser contemplados junto con los factores productivistas relacionados con la agricultura y la creación de empleo. (Arroyos, 2007. De Pablo, et al. 2006).

El nuevo enfoque del desarrollo rural en la Declaración de Cork produjo una aceleración de los acuerdos GATT (Acuerdo General sobre Aranceles de Aduana y Comercio), con la consecuente globalización comercial, mayores exigencias en la calidad de los alimentos por parte de los consumidores y la perspectiva de la ampliación comunitaria. Como resultado se produjo, en 1999, la Reforma de la Agenda 2000 que convirtió a la Política de Desarrollo Rural en el segundo pilar de la PAC. Sus principios fundamentales fueron la multifuncionalidad de la agricultura, el enfoque multisectorial e integrado de la economía rural (diversificación), la flexibilización de las ayudas al desarrollo rural (subsidiariedad), y la transparencia en la elaboración y la gestión de los programas (FODEPAL, 2006; MAPA, 2007). Se estableció que el desarrollo rural debía girar en torno a tres grandes ejes: refuerzo del sector agrario y forestal, mejora de la competitividad de las zonas rurales, y la preservación del medio ambiente y del entorno rural (MAPA, 2007).

Es a partir de la Agenda 2000 cuando se produce un cambio en la concepción del desarrollo rural dentro de la UE, materializado a través del Reglamento 1257/1999. La política rural se simplificó y Los Estados miembros tuvieron mayor capacidad de aplicación de las medidas, aplicando el principio de subsidiariedad (Martínez, 2006). Además, el Reglamento fue la base de la programación del periodo 2000-2006, y se consolidó la Iniciativa Comunitaria Leader. El reglamento se caracterizó por su enfoque nacional o regional descendente (top-down) y su limitado presupuesto. También, se instó a los Estados Miembros a presentar programas de desarrollo rural nacionales para el periodo 2000-2006.

Una nueva reforma en profundidad de la PAC se dio en 2003, centrándose en el consumidor y los contribuyentes, y dando a los agricultores mayor libertad para producir lo que el mercado demande. La reforma se materializó a través del Reglamento $1698 / 05$, con un marcado sesgo ambientalista y con un impulso al 
enfoque transversal, donde las acciones de desarrollo local son autogestionadas por las comunidades rurales. El nuevo reglamento estableció tres bloques de medidas a los cuales se denominó ejes, y se determinó un porcentaje mínimo de gasto para cada uno de ellos (Aumento de la competitividad del sector agrícola y forestal: 10\%, Mejora del medio ambiente y del entorno rural: $25 \%$, y Calidad de vida en las zonas rurales y diversificación de la economía rural: $10 \%$ ). El mayor porcentaje mínimo de inversión se destinó a medidas relacionadas con la conservación del ambiente. La Comisión no permitió ningún recorte de la propuesta de inversión (Arroyos, 2007. FODEPAL, 2007). Se caracterizó por ser un instrumento de Desarrollo Rural y no sólo de reestructuración agraria y por la limitación actual en el presupuesto.

Además, se dio un tratamiento horizontal a las actividades agrícolas y forestales, siendo beneficiarios igualitarios, y se creó una medida con el objetivo de otorgar pagos a las superficies incluidas en la Red Natura 2000, sin fondos propios para esta medida.

Para acceder a las ayudas de carácter ambiental se aplicó el principio de condicionalidad agraria (compensación por los compromisos ambientales cuando existe pérdida de ingresos), siendo un requisito que los agricultores debían aplicar las Buenas Prácticas Agrarias (Martínez, 2006).

La situación del periodo de programación 2000-2006 fue evaluado en la Segunda Conferencia Europea de Desarrollo Rural (2003), donde también se fijaron las directrices de las nuevas políticas a implementar y se definieron los objetivos para alcanzar un desarrollo sostenible en zonas rurales (Figura 2).

En las Directrices Estratégicas Comunitarias de Desarrollo Rural, para el periodo 2007-2013, se estableció que cada Estado miembro debe definir su plan estratégico nacional como marco de referencia para la elaboración de programas de desarrollo rural, los cuales debían contener un elemento LEADER para aplicar estrategias ascendentes de Desarrollo local a través de los Grupos de Acción Local (COAG, 2006; Comunidades Europeas, 2006; Palviainen, 2006). Éstas directrices se conectaron con las grandes prioridades europeas definidas en la Estrategia reformada de crecimiento y empleo de Lisboa y el objetivo de desarrollo sostenible de Gotemburgo (Arroyos, 2007). Se reestructuraron los recursos financieros en dos fondos:

a) el FEAGA (Fondo Europeo de Garantía Agraria), que sustituye al FEOGA, destinado a financiar el primer pilar de la PAC, y

b) el FEADER (Fondo Europeo Agrario de Desarrollo) que financia la política de Desarrollo Rural o segundo pilar de la PAC. 
Figura 2. Objetivos para alcanzar un desarrollo sostenible en zonas rurales.

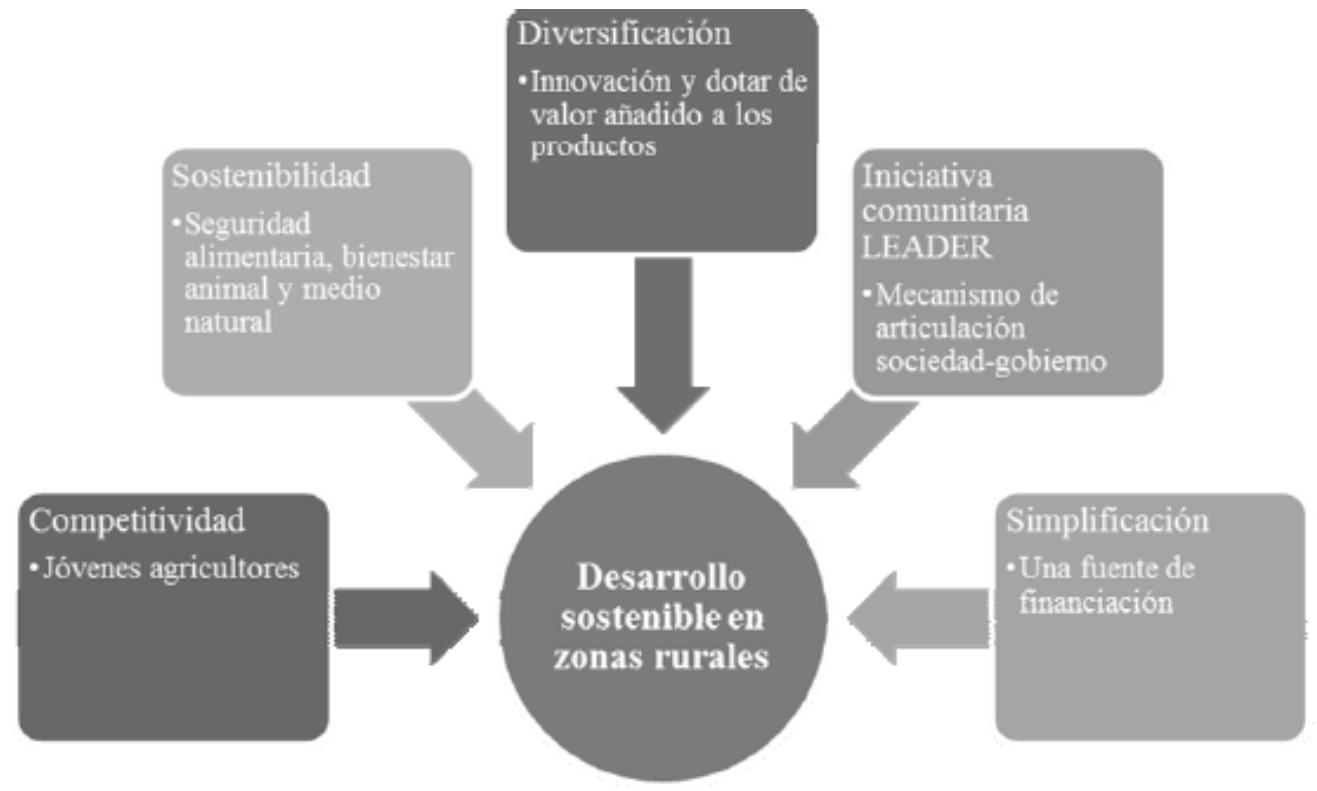

Fuente: Elaboración propia.

A través del Reglamento 1698/2005 se establecieron las normas generales que regulan la ayuda comunitaria al desarrollo rural, se definieron los objetivos a los que debe contribuir la política de desarrollo rural, el contexto estratégico (directrices estratégicas comunitarias - Reglamento 1698/2005) aplicables a la política de desarrollo rural y a los planes estratégicos nacionales, las prioridades y las medidas de desarrollo rural; y, se estableció una serie de normas relativas a la cooperación, la programación, la evaluación, la gestión financiera, el seguimiento y el control, sobre la base de las responsabilidades que comparten los Estados miembros y la Comisión (Comunidades Europeas, 2006).

Los ejes contemplados en este periodo estaban centrados en tres ámbitos fundamentales (ejes temáticos): la economía agroalimentaria, el medio ambiente y la economía y la población rural. Estos ejes fueron complementados con un eje metodológico, el programa LEADER. 
Figura 3. Evolución de la política del Desarrollo Rural en la Unión Europea.

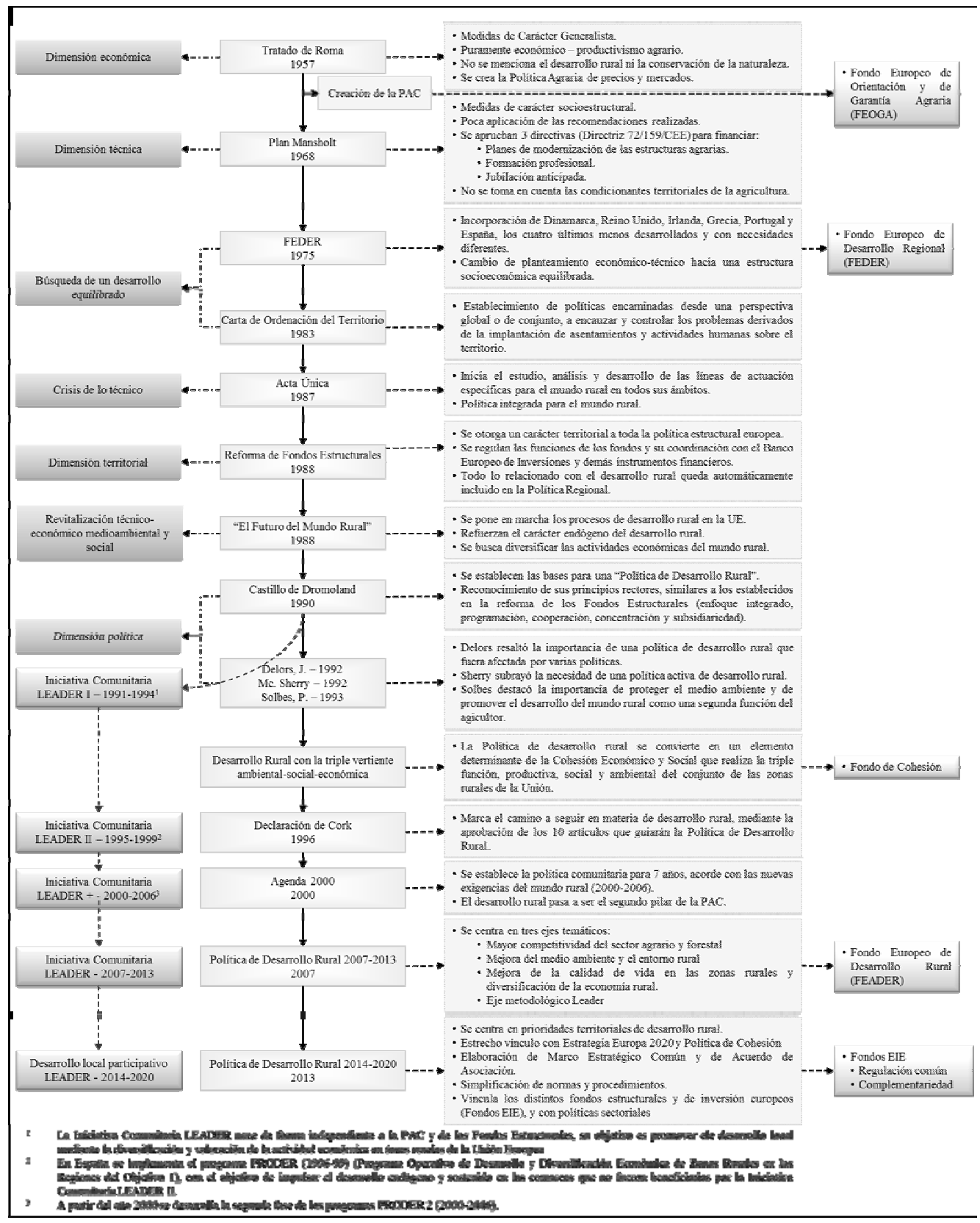

Fuente: Elaboración propia. 
Para Arroyos (2007), las medidas propuestas en el FEADER eran consideradas insuficientes para alcanzar un Desarrollo Rural adecuado, ya que se orientaban en satisfacer las demandas de los ciudadanos en materia de medioambiente, calidad y sanidad de los alimentos, y no en alcanzar una cohesión económica y social. Para la UE, en el periodo de programación 2007-2013 se alcanzaron los siguientes logros gracias a la política de cohesión:

a) La creación de 600000 trabajos, de los cuales aprox. 200000 fueron en el sector de las pymes.

b) La subvención a 200000 pymes.

c) La construcción o reconstrucción de $1.800 \mathrm{~km}$ de líneas ferroviarias.

d) La construcción o reconstrucción de $25000 \mathrm{~km}$ de carreteras.

e) El acceso de banda ancha por parte de 5 millones de ciudadanos.

f) El acceso a agua potable limpia por parte de 3 millones de ciudadanos.

g) 15 millones de participantes por año en el FSE.

h) La recaudación de 8360 millones EUR en los 25 Estados miembros por parte de 940 instrumentos financieros para fondos de cobertura, préstamos y garantías.

En la Figura 3 se resume la evolución de la política del Desarrollo Rural en la UE, iniciado en el Tratado de Roma de 1957 hasta el actual periodo de programación. Este último periodo, de 2014-2020, se amplía en el apartado 2.1.

\section{LA POLÍTICA DE DESARROLLO RURAL PARA EL PERIODO 2014-2020}

\subsection{NORMATIVA DE LA UNIÓN EUROPEA}

La última reforma de la política de desarrollo rural se dio en 2013, mediante la aprobación del Reglamento 1305/2013, y que se realizó junto con la reestructuración de la PAC. La nueva política está en concordancia con la Estrategia de la UE para un crecimiento inteligente, sostenible e integrador (Europa 2020), el desarrollo sostenible, el principio de que quien contamina paga, y con los objetivos generales de la PAC, estableciéndose como objetivos estratégicos a largo plazo para el periodo 2014-2020:

a) mejorar la competitividad de la agricultura.

b) garantizar la gestión sostenible de los recursos naturales y la acción por el clima.

c) lograr un desarrollo territorial equilibrado de las economías y comunidades rurales incluyendo la creación y conservación del empleo.

En relación con el periodo 2007-2013, en este nuevo periodo se habla de reforzar las mejoras alcanzadas a través de la nueva política de desarrollo rural, en los mismos ámbitos contemplados anteriormente: agricultura, medio ambiente y zonas rurales.

En el nuevo periodo de programación se han mantenido las principales características del periodo 2007-2013, entre ellas, la aplicación de la política de 
desarrollo rural a través de los programas de desarrollo rural (PDR) nacionales y/o regionales por periodos de siete años. Algunos de los cambios introducidos son:

- mejora el enfoque estratégico para elaborar los PDR, al elaborarse a partir del Marco Estratégico Común (MEC) y del Acuerdo de Asociación. Los PDR deben incluir al menos cuatro de las seis prioridades comunes de la UE (Tabla 1), que reflejan los objetivos temáticos del MEC.

Tabla 1. Relación entre las prioridades de desarrollo rural, los objetivos temáticos del MEC y los Fondos EIE de la Unión Europea para el periodo 2014-2020.

\begin{tabular}{|c|c|c|}
\hline Prioridades de desarrollo rural & Objetivos temáticos del MEC & $\begin{array}{l}\text { Fondos } \\
\text { EIE* }\end{array}$ \\
\hline $\begin{array}{l}\text { 1. Fomentar la transferencia de } \\
\text { conocimientos y la innovación en la } \\
\text { agricultura, la silvicultura y las zonas } \\
\text { rurales. }\end{array}$ & $\begin{array}{l}\text { - potenciar la investigación, el desarrollo tecnoló- } \\
\text { gico y la innovación (OT1) } \\
\text { - mejorar el uso y la calidad de las TICs, y el } \\
\text { acceso a las mismas (OT2); }\end{array}$ & FEDER \\
\hline $\begin{array}{l}\text { 2. Mejorar la viabilidad y la competi- } \\
\text { tividad de todos los tipos de agricul- } \\
\text { tura y promover las tecnologías } \\
\text { agrícolas innovadoras y la gestión } \\
\text { sostenible de los bosques }\end{array}$ & $\begin{array}{l}\text { - mejorar la competitividad de las pyme, del } \\
\text { sector agrícola y del sector de la pesca y la } \\
\text { acuicultura (OT3) }\end{array}$ & $\begin{array}{l}\text { FEDER } \\
\text { FEMP } \\
\text { FC }\end{array}$ \\
\hline $\begin{array}{l}\text { 3. Promover la organización de la } \\
\text { cadena alimentaria, el bienestar de los } \\
\text { animales y la gestión de riesgos en la } \\
\text { agricultura }\end{array}$ & $\begin{array}{l}\text { - promover la adaptación al cambio climático y la } \\
\text { prevención y gestión de riesgos (OT5) }\end{array}$ & $\begin{array}{l}\text { FEDER } \\
\text { FC }\end{array}$ \\
\hline $\begin{array}{l}\text { 4. Restaurar, conservar y mejorar los } \\
\text { ecosistemas dependientes de la } \\
\text { agricultura y la silvicultura }\end{array}$ & $\begin{array}{l}\text { - conservar y proteger el medio ambiente y } \\
\text { promover la eficiencia de los recursos }(\mathrm{OT} 6)\end{array}$ & $\begin{array}{l}\text { FEDER } \\
\text { FC }\end{array}$ \\
\hline $\begin{array}{l}\text { 5. Promover la eficiencia de los } \\
\text { recursos y apoyar el paso a una } \\
\text { economía hipocarbónica y adaptable } \\
\text { a los cambios climáticos en los } \\
\text { sectores agrícola, alimentario y } \\
\text { forestal. }\end{array}$ & $\begin{array}{l}\text { - favorecer la transición a una economía baja en } \\
\text { carbono en todos los sectores (OT4) } \\
\text { - promover el transporte sostenible y eliminar los } \\
\text { estrangulamientos en las infraestructuras de red } \\
\text { fundamentales (OT7) }\end{array}$ & $\begin{array}{l}\text { FEDER } \\
\text { FC }\end{array}$ \\
\hline $\begin{array}{l}\text { 6. Fomentar la inclusión social, la } \\
\text { reducción de la pobreza y el desarro- } \\
\text { llo económico en las zonas rurales. }\end{array}$ & $\begin{array}{l}\text { - promover la sostenibilidad y la calidad en el } \\
\text { empleo y favorecer la movilidad laboral (OT8) } \\
\text { - promover la inclusión social y luchar contra la } \\
\text { pobreza y cualquier forma de discriminación } \\
\text { (OT9) } \\
\text { - invertir en educación, formación y formación } \\
\text { profesional para la adquisición de capacidades y } \\
\text { un aprendizaje permanente (OT10) } \\
\text { - mejorar la capacidad institucional de las autori- } \\
\text { dades públicas y las partes interesadas y la } \\
\text { eficiencia de la administración pública (OT11) }\end{array}$ & $\begin{array}{l}\text { FEDER } \\
\text { FSE } \\
\text { FC }\end{array}$ \\
\hline
\end{tabular}

*El FEADER subvencionará medidas dentro de los subprogramas temáticos establecidos en los PDR.

Fuente: Elaboración propia. 
- refuerza el contenido de las medidas de desarrollo rural.

- simplifica las normas y/o reduce las cargas administrativas correspondientes cuando sea posible.

- vincula más estrechamente la política de desarrollo rural a los Fondos Estructurales y de Inversión Europeos (Fondos EIE) ${ }^{1}$, creando un marco regulador general (Reglamento 1303/2013) para los distintos fondos que ofrecen ayudas en el marco de las distintas políticas europeas relacionadas con las zonas rurales (opciones de costes simplificadas, gobernanza electrónica, normas de subvencionabilidad, instrumentos financieros, desarrollo local a cargo de las comunidades locales (DLCL)). Si bien se establece una regulación común (integración y coordinación para una mejor gobernzanza), también se establecen disposiciones específicas para cada uno de ellos, o grupo de ellos (Reglamento s1299/2013, 1301/2013 - FEDER y 1304/2013 - FSE). El FEADER mantendrá su funcionamiento y gestión, pero en coordinación con el resto de Fondos comunitarios.

Para el periodo 2014-2020 se han destinado 95.338.109.365 €, de los cuales aproximadamente el $60 \%$ van destinados a Polonia, Italia, Francia, España, Alemania y Rumanía (Figura 4). El 6\% es una reserva de rendimiento, que puede ser pública o privada, que se asignará en 2019 a programas y prioridades que hayan logrado el $85 \%$ de sus metas, de manera que se hace mayor énfasis en los resultados obtenidos, para ello se han establecido distintos tipos de controles: indicadores, informes de actividades, supervisiones y evaluaciones. Además, se ha destinado un $0.25 \%$ adicional para asistencia técnica $(238.942 .629 €)$.

La articulación del nuevo periodo de programación está basado en la relación: programación, asociación y gestión compartida, que se esquematiza en la Figura 5. La gestión de los programas y la aplicación de la política de cohesión se realizará mediante tres autoridades de gestión: la autoridad de gestión para aplicar el programa operativo y un comité de seguimiento para supervisarlo, el organismo de certificación para verificar la declaración de gastos y las solicitudes de pago antes de su envío a la Comisión, y el organismo auditor para cada programa operativo que supervisará la eficacia del sistema de gestión y seguimiento.

${ }^{1}$ Los fondos EIE regulados son:

a) Fondos para la política de cohesión: FEDER (Fondo Europeo de Desarrollo Regional), FSE (Fondo Social Europeo), FC (Fondo de Cohesión).

b) Fondo para el desarrollo rural: FEADER (Fondo Europeo Agrícola de Desarrollo Rural).

c) Fondo del sector marítimo y de la pesca (FEMP): Título V del Fondo Europeo Marítimo y de la Pesca. 
Figura 4. Distribución de los fondos para el periodo de programación 2014-2020.

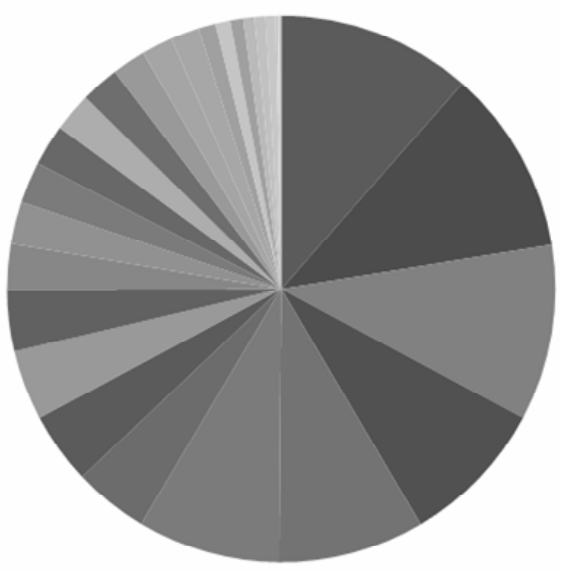

\begin{tabular}{|c|c|}
\hline Polonia & Italia \\
\hline Francia & España \\
\hline Alemania & - Rumanía \\
\hline Grecia & — Portugal \\
\hline Austria & - Hungría \\
\hline Reino Unido & - Finlandia \\
\hline Bulgaria & Croacia \\
\hline Irlanda & a Chequia \\
\hline Eslovaquia & Suecia \\
\hline Lituania & Letonia \\
\hline Eslovenia & Estonia \\
\hline Dinamarca & Países Bajo \\
\hline = Bélgica & = Chipre \\
\hline Luxemburgo & Malta \\
\hline
\end{tabular}

Fuente: Elaboración propia.

A modo de resumen, el FEDER pondrá énfasis en la inversión a empresas (infraestructuras, empresas de servicios, apoyo a la actividad empresarial, TICs, e innovación e investigación) y la prestación de servicios (energía, servicios en línea, educación, sanidad, infraestructuras sociales y de investigación, accesibilidad, calidad del medio ambiente). El FSE se centrará principalmente en los objetivos temáticos de empleo y movilidad laboral, educación, competencias y aprendizaje permanente; promoción de la inclusión social y lucha contra la exclusión social, y refuerzo de la capacidad administrativa. El FEDER y el FSE financiarán acciones y medidas en todas las regiones europeas, mientras que el FC solo beneficiará a los Estados miembros con un PIB inferior al 90\% de la media de la UE (Tiana, 2013). La transferencia de conocimientos y la innovación, la competitividad de la agricultura, la gestión de los recursos naturales y la acción por el clima, y el desarrollo integrador de las zonas rurales serán las prioridades del FEADER. En las zonas pesqueras actuará el FEMP, en coherencia con la Política Pesquera Común.

Figura 5. Articulación del periodo de programación 2014-2020.

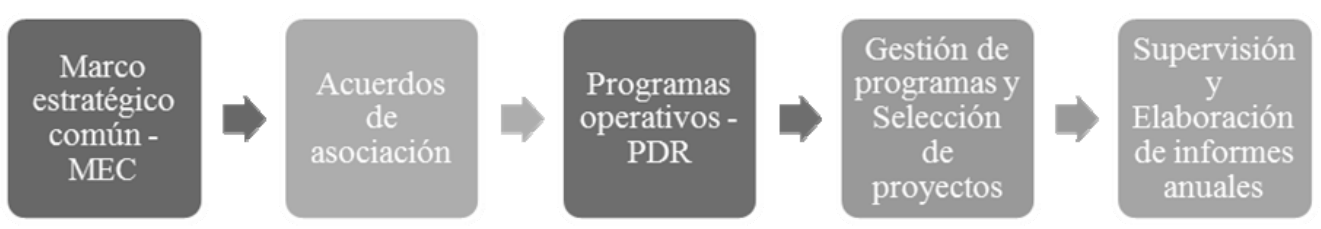

Fuente: Elaboración propia. 
Tiana (2013) destaca que el FEDER requiere que en las regiones desarrolladas y en transición se realicen el $80 \%$ de las intervenciones, y un $50 \%$ de ellas en las regiones menos desarrolladas en el marco de las prioridades 1,3 y 4 (mínimo 20\%). Además, cada Estado miembro destinará el $5 \%$ de los recursos a iniciativas urbanas. Existiendo un debate sobre la definición de urbano, de manera que se puedan incluir áreas metropolitas, ciudades medias y redes de ciudades (Tiana, 2013).

\subsection{MARCO ESTRATÉGICO COMÚN (MEC)}

El Marco Estratégico Común elaborado por la UE, que consta en el Reglamento 1303/2013, establece los siguientes aspectos:

- Contribución de los Fondos EIE a Estrategia Europa 2020 y coherencia con la gobernanza económica de la UE.

- Enfoque integrado y medidas para la utilización de los Fondos EIE.

- Coordinación y sinergias entre los Fondos EIE y otros instrumentos y políticas de la UE

- Principios horizontales y objetivos políticos transversales

- Disposiciones para hacer frente a los principales retos territoriales

- Actividades de cooperación

El MEC se caracteriza por establecer los principios rectores estratégicos para la coordinación efectiva, tanto sectorial como territorial, de los Fondos EIE, y de otros instrumentos y políticas europeos (Horizonte 2020, $\mathrm{COSME}^{2}$, Programa NER $300^{3}$, LIFE $^{4}$, ERASMUS, PEIS ${ }^{5}$, Mecanismo «Conectar Europa», Instrumento de Ayuda Preadhesión, Instrumento Europeo de Vecindad y Fondo Europeo de Desarrollo) relacionados con las metas y los objetivos de la estrategia Europa 2020. Para ello, los traduce en acciones clave y prioridades de inversión, manteniendo la coherencia con los PNR, y con las misiones de los Fondos EIE, incluida la cohesión económica, social y territorial, para alcanzar un desarrollo integrado. También establece la estrategia de inversión global de todos los Fondos EIE, considerando los retos territoriales clave para cada tipo de territorio. No se imponen obligaciones a los Estados miembros más allá de las establecidas en el marco de las políticas sectoriales. En la Figura 6 se presentan los principales aspectos contemplados en el MEC, y a continuación se resumen las principales características.

\footnotetext{
${ }^{2}$ Programa para la Competitividad de las Empresas y para las Pequeñas y Medianas Empresas

${ }^{3}$ Programa Reserva de Nuevos Entrantes (NER) 300

${ }^{4}$ Programa de Medio Ambiente y Acción por el Clima

${ }^{5}$ Programa de la Unión Europea para el Empleo y la Innovación Social
} 
Se establece que la mayor prioridad de gasto de los Fondos EIE se dará en cuatro áreas clave para el crecimiento de la UE, de acuerdo con la Estrategia Europa 2020: educación e I+D+i, TICs, competitividad de pymes y mayor financiación (mayor uso de instrumentos financieros), y sostenibilidad ambiental y eficiencia energética y energías renovables (transición hacia una economía de bajas emisiones de $\mathrm{CO}_{2}$ ). Se dará especial impulso, a través de estas prioridades, al empleo, especialmente juvenil, y la inclusión social.

Figura 6. Aspectos principales del MEC.

\begin{tabular}{|c|c|}
\hline $\begin{array}{l}\text { Programación estratégica y } \\
\text { concentración de prioridades }\end{array}$ & $\begin{array}{l}\text {-Europa } 2020 \\
\text { • Objetivos temáticos del MEC }\end{array}$ \\
\hline $\begin{array}{l}\text { Programación integraday mayor } \\
\text { coordinación entre Fondos EIE }\end{array}$ & $\begin{array}{l}\text { - Desarrollo local participativo } \\
\text {-Inversión Territorial Integrada }\end{array}$ \\
\hline $\begin{array}{l}\text { Condicionalidady recompensa al } \\
\text { rendimiento }\end{array}$ & $\begin{array}{l}\text { - Condiciones ex ante } \\
\text { - Condiciones ex post (reserva de rendimiento) } \\
\text { - Condiciones macroecnómicas }\end{array}$ \\
\hline $\begin{array}{c}\text { Innovación y Especialización } \\
\text { Inteligente }\end{array}$ & $\begin{array}{l}\text { - Estrategias RIS3 } \\
\text {-Inversión en potencialidades } \\
\text { - Colaboración empresas, centros de I+D+i y universidades } \\
\text {-Vínculo entre Fondos EIE y Programa Horizonte } 2020\end{array}$ \\
\hline Dimensión territorial & $\begin{array}{l}\text { - Objetivo: Cohesión territorial } \\
\text {-Método: enfoque territorial }\end{array}$ \\
\hline $\begin{array}{l}\text { Recomendaciones especificas por } \\
\text { país }\end{array}$ & $\begin{array}{l}\text { - Prioridades } \\
\text { - Objetivos temáticos }\end{array}$ \\
\hline
\end{tabular}

Fuente: Elaboración propia.

Los Estados miembros y los responsables de los Fondos EIE serán responsables de alcanzar la máxima eficacia, coordinación, sinergia y complementariedad entre los Fondos EIE. Se busca que la combinación de fondos a distintas escalas territoriales responda de mejor manera a los retos propios de cada territorio, para ello se promoverán las inversiones territoriales integradas (gestión de PDR en varias), las operaciones integradas, los planes de acción conjuntos y el desarrollo local participativo (gestión público-privada a partes iguales con meotodología Leader). Éste último será definido por cada Estado miembro para su territorio, y las distintas estrategias locales deberán ser coherentes con la definición nacional de desarrollo local participativo. El desarrollo local participativo y las inversiones territoriales integradas promoverán enfoques integrados para el desarrollo territorial (Gallardo, 2013).

En relación con los principios horizontales y objetivos políticos transversales, se establecen criterios relacionados con la asociación y gobernanza, el desarrollo sostenible, la igualdad y no discriminación, accesibilidad, el cambio demográfico, y el cambio climático. 
- La asociación y gobernanza multinivel, que se quiere promover, deberá realizarse de acuerdo con los principios de subsidiariedad y proporcionalidad, fortaleciendo los Estados miembros, en caso de ser necesario, la capacidad institucional de los socios.

- Se deberá garantizar que las intervenciones causen el menor impacto posible en el medio ambiente y el mayor beneficio social, medioambiental y climático (reducción de los efectos del cambio climático). Para ello se recomienda promover inversiones más sostenibles y eficientes en recursos, que no causen impactos negativos importantes, y con perspectiva a largo plazo en función de los costes de ciclo de vida. Así también, que se recurra en mayor medida a la contratación pública ecológica.

- La promoción de la igualdad entre hombres y mujeres y no discriminación estará financiada principalmente por el FSE, y deberá realizarse en todas las fases de los programas (preparación, ejecución, seguimiento y evaluación). Se recomienda que organismos relacionados con este tema sean socios activos. Deberá promoverse la inclusión de grupos desfavorecidos en el mercado laboral.

- Garantizar una mayor accesibilidad general al entorno físico, el transporte y las TICs por parte de las personas con discapacidad y los ancianos, es otro principio horizontal que se deberá cumplir. Pudiendo financiarse infraestructuras relacionadas con la accesibilidad de los edificios existentes y los servicios establecidos para este fin.

- Se requiere abordar el cambio demográfico para combatir la disminución de la población activa, el incremento del número de jubilados y la despoblación. Para ello, se recomienda la mejora del acceso a la educación y a las estructuras de apoyo social (protección social, dependencia, asistencia sanitaria, etc.) para mejorar las oportunidades de empleo de jóvenes y de personas de mayor edad, especialmente en las regiones con desempleo juvenil superior a la media europea.

Para hacer frente a los principales retos territoriales clave se dispone que los Estados miembros deben tener en cuenta las características geográficas o demográficas (Figura 7) de las distintas regiones que componen la UE (zonas urbanas, rurales, litorales y pesqueras), así como también su potencial de desarrollo específico, y el impacto potencial que puede sufrir cada una de las regiones por los desafíos sociales actuales (mundialización, cambio demográfico, degradación medioambiental, migración, cambio climático, uso de la energía, consecuencias económicas y sociales de la crisis). 
Figura 7. Principales aspectos de diversidad de las regiones europeas.

\begin{tabular}{|c|c|c|c|c|c|}
\hline $\begin{array}{c}\text { Empleo y } \\
\text { mercado de } \\
\text { trabajo }\end{array}$ & $\begin{array}{c}\text { Interdependenc } \\
\text { ias entre } \\
\text { sectores }\end{array}$ & $\begin{array}{c}\text { Patrones de } \\
\text { desplazamiento }\end{array}$ & $\begin{array}{c}\text { Envejecimiento } \\
\text { de la población } \\
\text { / Cambios } \\
\text { demográficos }\end{array}$ & $\begin{array}{c}\text { Particularidade } \\
\text { s culturales, } \\
\text { topográficas y } \\
\text { patrimoniales }\end{array}$ & $\begin{array}{c}\text { Vulnerabilidad } \\
\text { al cambio } \\
\text { climático }\end{array}$ \\
\cline { 1 - 2 } $\begin{array}{c}\text { Uso del suelo y } \\
\text { limitación de } \\
\text { recursos }\end{array}$ & $\begin{array}{c}\text { Uso sostenible } \\
\text { de los recursos } \\
\text { naturales }\end{array}$ & $\begin{array}{c}\text { Gobernanza e } \\
\text { instituciones }\end{array}$ & $\begin{array}{c}\text { Conectivdad y } \\
\text { accesibilidad }\end{array}$ & $\begin{array}{c}\text { Conexiones } \\
\text { urbano-rural }\end{array}$ \\
\hline
\end{tabular}

Fuente: Elaboración propia.

Los Estados miembros y las regiones deberán adoptar medidas para preparar sus acuerdos de asociación y sus PDR. Entre ellas: analizar las características, el potencial y la capacidad de desarrollo; evaluar los principales retos que deben abordarse; evaluar los retos de coordinación intersectorial, transfronteriza o interjurisdiccional, especialmente en el marco de estrategias macrorregionales y de cuencas marítimas; y determinar las medidas para lograr una mejor coordinación multinivel. Esta evaluación de las condiciones ex ante busca que los Estados miembros cumplan los requisitos necesarios para una ejecución eficaz de los Fondos EIE. También, se establece un sistema de incentivos (condiciones ex post) para recompensar a los territorios en función de los resultados alcanzados (reserva de rendimientos).

En el ámbito de la innovación y la especialización inteligente, se ha incluido a las Estrategias de Investigación e Innovación para la especialización inteligente (RIS3), como una condición ex ante. Al igual que en otros ámbitos, se centrarán los recursos en las áreas de especialización más prometedoras, articulando la relación empresas, centros de $\mathrm{I}+\mathrm{D}+\mathrm{i}$ y universidades. Gallardo (2013) resala la importancia dada al vínculo existente entre los Fondos EIE y el Programa Horizonte 2020.

Para una mayor cohesión territorial, se deberá tomar en cuenta a las zonas que sufren desventajas geográficas o demográficas específicas; a las regiones más septentrionales con muy baja densidad de población y las regiones insulares, transfronterizas y de montaña; las relaciones ciudad-campo en términos de acceso a servicios e infraestructuras; y regiones con alta concentración de grupos o colectivos marginados socialmente. Dado que la cohesión territorial se convierte en un objetivo prioritario, el trasladar la dimensión territorial al diseño de políticas e intervenciones será complicado, principalmente porque las políticas públicas han estado dominadas por perspectivas sectoriales, generalmente ajenas y alejadas de la perspectiva territorial (Gallardo, 2013). Cada Estado miembro definirá a las zonas rurales y territorios, en función de sus propias características, lo que dificultará obtener una definición armonizada de la noción de "territorios" en relación con los Fondos EIE.

Además de la coordinación y complementariedad de los Fondos EIE, los Estados miembros también deberán trabajar en otros ámbitos prioritarios de coordinación y complementariedad como son: entre los programas en el marco del objetivo de cooperación territorial europea y del objetivo de inversión en crecimiento y empleo 
(inversiones a gran escala), para que refuercen la política de cohesión territorial; los objetivos de estrategias macrorregionales y de las cuencas marítimas que formen parte de la planificación estratégica global en los acuerdos de asociación; y las acciones interregionales y transnacionales para el crecimiento y empleo, incluidas medidas de $\mathrm{I}+\mathrm{D}+\mathrm{i}$.

Para Gallardo (2013), el nuevo MEC representa un cambio de paradigma en relación con el periodo 2007-2013, en aspectos como la gobernanza de los fondos, los compromisos compartidos, la participación público privada, la inclusión social, la focalización territorial, la innovación y la especialización inteligente.

En el marco del FEDER, se reforzará la cooperación transfronteriza, transnacional e interregional en ámbitos como TICs, I+D+i, e instituciones educativas. De igual manera, utilizar la cooperación transfronteriza y transnacional para: la gestión conjunta y la promoción de los recursos naturales, el uso compartido de servicios públicos (explotar economías de escala), infraestrucruras y transporte respetuosos con el medio ambiente, la competitividad de las pymes ( $+\mathrm{D}+\mathrm{i}$, TICs y educación), la movilidad de trabajadores, y la gobernanza. Se financiarán proyectos en ámbitos como el patrimonio cultural y natural o el turismo siempre que estén estrechamente relacionados con los objetivos temáticos (Tiana, 2013). En el marco del FSE, los ámbitos políticos de cooperación transnacional serán definidos por el Consejo Europeo, para sacar el máximo provecho del aprendizaje mutuo. Los temas de las actividades transnacionales y los mecanismos de aplicación serán seleccionados y establecidos por los Estados miembros, en función de sus necesidades específicas.

\subsection{CONDICIONES EX ANTE}

Para elaborar tanto los Acuerdos de Asociación, como los PDR, cada Estado miembro debe evaluar sus condiciones ex ante para determinar si son coherentes con los objetivos específicos de los PDR y, las normas específicas de los Fondos EIE y las condiciones generales establecidas en el Reglamento 1303/2013. El cumplimiento de las condiciones busca garantizar una inversión efectiva de los fondos EIE. Las condiciones ex ante generales están vinculadas a los aspectos horizontales de la ejecución del programa y de aplicación a todos los Fondos ESI. En la evaluación de la aplicabilidad se tendrá en cuenta el principio de proporcionalidad asociado al nivel de ayuda asignado.

Las condiciones ex ante temáticas están vinculadas a los objetivos temáticos y a las prioridades de inversión de la política de cohesión. Deberán estar aplicadas en relación con las inversiones en el área temática específica: condiciones previas estratégicas, normativas e institucionales, y capacidad administrativa. En la Tabla 2 se resumen las condiciones que deben incluir en la evaluación ex ante los Estados miembros. 
Tabla 2. Resumen de las condiciones ex ante temáticas

\begin{tabular}{|c|c|}
\hline Condiciones ex ante & Criterios de cumplimiento \\
\hline \multicolumn{2}{|c|}{ OT1. Potenciar la investigación, el desarrollo tecnológico y la innovación (objetivo de $I+D$ ) } \\
\hline $\begin{array}{l}\text { 1.Investigación e } \\
\text { innovación }(\mathrm{I}+\mathrm{i})\end{array}$ & $\begin{array}{l}\text { - Estrategia nacional o regional para una especialización inteligente } \\
\text { (estrategias de RIS3). } \\
\text { - Marco con los recursos presupuestarios disponibles para la I+i. }\end{array}$ \\
\hline $\begin{array}{l}\text { 2.Infraestructuras de } \\
\mathrm{I}+\mathrm{i}\end{array}$ & $\begin{array}{l}\text { - Plan plurianual indicativo de presupuestación y priorización de inver- } \\
\text { siones. }\end{array}$ \\
\hline \multicolumn{2}{|c|}{ OT2. Mejorar el uso y la calidad de las TICs y el acceso a las mismas (objetivo de banda ancha) } \\
\hline 1.Crecimiento digital & - Marco estratégico sobre crecimiento digital. \\
\hline $\begin{array}{l}\text { 2.Infraestructura de } \\
\text { RPG }\end{array}$ & - Plan nacional o regional de red de próxima generación (RPG). \\
\hline \multicolumn{2}{|c|}{$\begin{array}{l}\text { OT3. Mejorar la competitividad de las pequeñas y medianas empresas (pymes) y del sector de la } \\
\text { pesca y la acuicultura (en el caso del FEMP) }\end{array}$} \\
\hline $\begin{array}{l}\text { 1. Acciones específi- } \\
\text { cas }\end{array}$ & $\begin{array}{l}\text { - Para sostener la promoción del espíritu empresarial teniendo en cuenta } \\
\text { la Iniciativa en favor de las pequeñas empresas (SBA): } \\
\text { - medidas para reducir el tiempo y los costes de creación de una em- } \\
\text { presa. } \\
\text { - medidas para reducir el plazo de obtención de licencias y permisos. } \\
\text { - mecanismo de seguimiento de la aplicación de las medidas de la } \\
\text { iniciativa SBA y evaluar el impacto de la legislación en las pymes. }\end{array}$ \\
\hline \multicolumn{2}{|c|}{ OT4. Favorecer la transición a una economía baja en carbono en todos los sectores } \\
\hline $\begin{array}{l}\text { 1. Acciones para } \\
\text { fomentar la eficiencia } \\
\text { energética de los } \\
\text { edificios (EEE) }\end{array}$ & $\begin{array}{l}\text { - Medidas con requisitos mínimos de EEE. } \\
\text { - Medidas para sistema de certificación de EEE. } \\
\text { - Medidas para asegurar la planificación estratégica sobre eficiencia } \\
\text { energética. }\end{array}$ \\
\hline $\begin{array}{l}\text { 2. Acciones de } \\
\text { fomento de la cogene- } \\
\text { ración de calor }\end{array}$ & $\begin{array}{l}\text { Estimular el diseño de unidades de cogeneración para cubrir la deman- } \\
\text { da económicamente justificable de calor útil y evitar la sobreproduc- } \\
\text { ción. } \\
\text { - Reducir los obstáculos reglamentarios y no reglamentarios. }\end{array}$ \\
\hline $\begin{array}{l}\text { 3. Acciones para } \\
\text { fomentar la produc- } \\
\text { ción y distribución de } \\
\text { fuentes de energía } \\
\text { renovables }\end{array}$ & $\begin{array}{l}\text { - Sistemas de apoyo transparentes, prioridad de acceso a la red y de } \\
\text { suministro, y normas estándar para el reparto de los costes de las adap- } \\
\text { taciones técnicas. } \\
\text { - Plan de acción nacional en materia de energía renovable. }\end{array}$ \\
\hline \multicolumn{2}{|c|}{$\begin{array}{l}\text { OT5. Promover la adaptación al cambio climático, la prevención de riesgos y la gestión (objetivo } \\
\text { sobre cambio climático) }\end{array}$} \\
\hline $\begin{array}{l}\text { 1. Prevención y } \\
\text { gestión de riesgos }\end{array}$ & $\begin{array}{l}\text { - Evaluación de riesgos nacional o regional, para la gestión de las } \\
\text { catástrofes, teniendo en cuenta la adaptación al cambio climático. }\end{array}$ \\
\hline \multicolumn{2}{|c|}{ OT6. Preservar y proteger el medio ambiente y promover la eficiencia energética } \\
\hline 1. Sector del agua & $\begin{array}{l}\text { - Política de tarificación del agua para un uso eficiente de los recursos } \\
\text { hídricos. } \\
\text { - Contribución adecuada de los diversos usos del agua a la recuperación } \\
\text { de los costes de los servicios relacionados (en sectores apoyados por } \\
\text { FEDER y FC). } \\
\text { - Plan hidrológico de cuenca para la demarcación hidrográfica. }\end{array}$ \\
\hline
\end{tabular}


2. Sector de los residuos
- Informe de los avances en los objetivos de la Directiva 2008/98/CE.

- Uno o varios planes de gestión de recursos (con inversiones).

- Programas de prevención de residuos.

- Medidas para alcanzar los objetivos de 2020 de preparación sobre reutilización y reciclado.

OT7. Promover el transporte sostenible y eliminar los estrangulamientos en las infraestructuras de red fundamentales

1. Transporte - Uno o varios planes o marcos globales de transporte (inversión) que apoyen el desarrollo de la estructura y mejoren la conectividad de la RTE-T.

- Medidas para garantizar la capacidad de los organismos intermedios y de los beneficiarios para ejecutar el programa de proyectos (para todos los modos de transporte, incluido ferrocarril y otros modos).

\begin{tabular}{|c|c|}
\hline 2. Ferrocarril & - Sección sobre el desarrollo ferroviario. \\
\hline $\begin{array}{l}\text { 3. Otros modos de } \\
\text { transporte }\end{array}$ & $\begin{array}{l}\text { - Sección sobre la infraestructura de navegación interior y transporte } \\
\text { marítimo, puertos, vínculos multimodales y aeropuertos. }\end{array}$ \\
\hline $\begin{array}{l}4 \text { Sistemas inteligen- } \\
\text { tes de distribución, } \\
\text { almacenamiento y } \\
\text { transmisión de energía }\end{array}$ & $\begin{array}{l}\text { - Planes globales de inversión en infraestructuras inteligentes de energía } \\
\text { que describen las prioridades de infraestructura nacional de energía, y } \\
\text { que contribuyan a mejorar la eficiencia energética y la seguridad del } \\
\text { suministro. }\end{array}$ \\
\hline \multicolumn{2}{|c|}{$\begin{array}{l}\text { OT8. Promover la sostenibilidad y la calidad en el empleo y favorecer la movilidad laboral (objeti- } \\
\text { vo de empleo) }\end{array}$} \\
\hline $\begin{array}{l}\text { 1. Políticas activas del } \\
\text { mercado de trabajo }\end{array}$ & $\begin{array}{l}\text { - Servicios personalizados y medidas activas y preventivas del mercado } \\
\text { de trabajo. Incluido información de nuevos puestos de trabajo. } \\
\text { - Especial atención a grupos con mayor riesgo de exclusión social. } \\
\text { - Acuerdos de cooperación, formales o informales, con las partes } \\
\text { interesadas. }\end{array}$ \\
\hline $\begin{array}{l}\text { 2. Trabajo por cuenta } \\
\text { propia, espíritu } \\
\text { emprendedor y } \\
\text { creación de empresas }\end{array}$ & $\begin{array}{l}\text { - Marco estratégico para la creación inclusiva de empresas con medidas } \\
\text { para reducir tiempo y coste de creación de empresas, de obtención de } \\
\text { licencias y permisos, y de acceso al capital. }\end{array}$ \\
\hline $\begin{array}{l}\text { 3. Las instituciones } \\
\text { del mercado de } \\
\text { trabajo son moderni- } \\
\text { zadas y reforzadas }\end{array}$ & $\begin{array}{l}\text { - Marco estratégico claro y una evaluación ex ante (con inclusión de la } \\
\text { dimensión de género), con la inclusión de las medidas de la condición } \\
1 \text {. }\end{array}$ \\
\hline $\begin{array}{l}\text { 4. Envejecimiento } \\
\text { activo y saludable }\end{array}$ & $\begin{array}{l}\text { - Políticas de envejecimiento activo. Los partes interesadas participan en } \\
\text { su elaboración y seguimiento. } \\
\text { - Medidas para fomentar el envejecimiento activo. }\end{array}$ \\
\hline $\begin{array}{l}\text { 5. Adaptación al } \\
\text { cambio de los trabaja- } \\
\text { dores, las empresas y } \\
\text { los emprendedores }\end{array}$ & $\begin{array}{l}\text { - Políticas destinadas a favorecer la anticipación y la buena gestión del } \\
\text { cambio y la reestructuración. }\end{array}$ \\
\hline $\begin{array}{l}\text { 6. Marco estratégico } \\
\text { para promover el } \\
\text { empleo de los jóvenes }\end{array}$ & $\begin{array}{l}\text { - Basado en datos de los jóvenes que ni tienen trabajo, ni estudian ni } \\
\text { siguen ninguna formación. } \\
\text { - Determina la autoridad pública encargada de gestionar las medidas y } \\
\text { de coordinar las asociaciones. } \\
\text { - Medidas de apoyo al acceso al empleo, a la mejora de las aptitudes, a } \\
\text { la movilidad laboral y a la integración sostenible en el mercado labo- } \\
\text { ral. }\end{array}$ \\
\hline
\end{tabular}


OT9. Promover la inclusión social, luchar contra la pobreza y cualquier tipo de discriminación (objetivo sobre pobreza)

1. Marco estratégico - Datos concretos suficientes para la elaboración de políticas de reducnacional para la reducción de la pobreza y exclusión social ción de la pobreza y el seguimiento de los cambios.

- Medidas de apoyo para lograr el objetivo nacional (definido en el PNR).

- Promoción de las oportunidades de empleo sostenible y de calidad.

- Implica a las partes interesadas pertinentes, quienes pueden presentar, ejecutar y gestionar proyectos.

- Medidas para cambiar la asistencia institucional por una asistencia de carácter local.

2. Marco estratégico nacional de inclusión de los gitanos

- Con objetivos nacionales realizables de integración (incluidos educación, empleo, asistencia sanitaria y vivienda).

- Identificación de microrregiones desfavorecidas o segregadas.

- Mecanismos de seguimiento para evaluar las políticas implementadas.

- Las partes interesadas pueden presentar, ejecutar y gestionar proyectos.

\begin{tabular}{ll}
\hline 3. Marco estratégico & - Medidas coordinadas para mejorar el acceso a servicios sanitarios. \\
nacional o regional en & - Medidas destinadas a estimular la eficiencia en el sector sanitario. \\
materia de salud & - Sistema de seguimiento y revisión. \\
\hline
\end{tabular}

OT10. Invertir en la educación, la formación, incluida la formación profesional, para el desarrollo de las capacidades y el aprendizaje permanente (objetivo de educación)

\begin{tabular}{|c|c|}
\hline $\begin{array}{l}\text { 1. Marco estratégico } \\
\text { para reducir el } \\
\text { abandono escolar } \\
\text { prematuro (AEP) }\end{array}$ & $\begin{array}{l}\text { - Sistema de recogida y análisis de datos e información con datos } \\
\text { concretos y suficientes para elaborar políticas específicas y hacer se- } \\
\text { guimiento. } \\
\text { - Destinado en particular a grupos vulnerables. } \\
\text { - Implica a todos los sectores de actuación y partes interesadas }\end{array}$ \\
\hline $\begin{array}{l}\text { 2. Marco estratégico } \\
\text { nacional o regional } \\
\text { para aumentar las } \\
\text { titulaciones de la } \\
\text { educación superior, su } \\
\text { calidad y eficacia }\end{array}$ & $\begin{array}{l}\text { - Medidas para incrementar la participación (grupos con ingresos bajos } \\
\text { y subrepresentados), las titulaciones (reducción del abandono o au- } \\
\text { mento de las tasas de titulaciones) y, los contenidos y programas inno- } \\
\text { vadores. } \\
\text { - Medidas para mejorar la empleabilidad y el espíritu emprendedor, } \\
\text { reduciendo las diferencias de género. }\end{array}$ \\
\hline $\begin{array}{l}\text { 3. Marco estratégico } \\
\text { nacional o regional en } \\
\text { materia de aprendizaje } \\
\text { permanente }\end{array}$ & $\begin{array}{l}\text { - Medidas para restar apoyo a la creación y vinculación de servicios para } \\
\text { el aprendizaje permanente (AP). } \\
\text { - Medidas para el desarrollo de las capacidades de grupos destinatarios } \\
\text { (jóvenes en formación profesional, adultos, con baja cualificación, } \\
\text { migrantes, etc.). } \\
\text { - Medidas para ampliar el acceso al AP. } \\
\text { - Medidas para mejorar la pertinencia para el mercado laboral de la } \\
\text { educación y la formación y adaptarlas a las necesidades de grupos } \\
\text { destinatarios concretos. }\end{array}$ \\
\hline $\begin{array}{l}\text { 4. Marco estratégico } \\
\text { nacional o regional } \\
\text { para aumentar la } \\
\text { calidad y la eficacia } \\
\text { de los sistemas de } \\
\text { formación profesional }\end{array}$ & $\begin{array}{l}\text { - Medidas para mejorar la pertinencia para el mercado laboral de los } \\
\text { sistemas de formación profesional. } \\
\text { - Medidas para aumentar la calidad y el atractivo de la formación } \\
\text { profesional. }\end{array}$ \\
\hline
\end{tabular}


OT11. Mejorar la capacidad institucional de las autoridades públicas y las partes interesadas y la eficiencia de la administración pública

\begin{tabular}{|c|c|}
\hline $\begin{array}{l}\text { 1. Marco estratégico } \\
\text { para mejorar la } \\
\text { eficiencia administra- } \\
\text { tiva }\end{array}$ & $\begin{array}{l}\text { - Análisis y planificación estratégica de las medidas de reforma jurídica, } \\
\text { organizativa o procedimental. } \\
\text { - Sistemas de gestión de la calidad. } \\
\text { - Acciones integradas para la simplificación y racionalización de los } \\
\text { procedimientos administrativos. } \\
\text { - Desarrollo y aplicación de estrategias y políticas en materia de recur- } \\
\text { sos humanos que abarcan las principales carencias. } \\
\text { - Desarrollo de capacidades a todos los niveles de la jerarquía profesio- } \\
\text { nal dentro de las autoridades públicas }\end{array}$ \\
\hline
\end{tabular}

Fuente: Elaboración propia.

Las disposiciones de formación, y difusión de la información, deben estar dirigidas al personal de las autoridades que participan en la gestión y control de los Fondos EIE. En el ámbito de la legislación sobre medio ambiente, estas disposiciones estarán dirigidas para el personal que participa en la ejecución de las Directivas.

La base estadística nacional permitirá evaluar la eficacia y el impacto de los programas a desarrollar, y el sistema de indicadores de resultados, seleccionar las medidas que contribuyan más eficazmente a obtener los resultados esperados, hacer un seguimiento de los avances y realizar la evaluación de impacto.

Se han establecido siete ámbitos para analizar las condiciones ex ante generales (existencia de capacidad administrativa de ejecución y/o de legislación europea y/o nacional, en el ámbito de los Fondos EIE), cuyo resumen deberá ser incluido en el Acuerdo de Asociación. Los criterios de cumplimiento verificarán la existencia de disposiciones acordes con el marco institucional y jurídico de los Estados miembros en los distintos ámbitos, durante la elaboración y aplicación de los programas (Tabla 3). Si el Estado miembro no cumple los criterios de cumplimiento, debe indicar las medidas a tomar, los organismos responsables y el calendario de aplicación. El plazo para cumplir los criterios es finales de 2016. En caso de cumplirlos, la Comisión podrá suspender la totalidad o parte de los pagos intermedios, reanudándolos una vez se cumplan. Únicamente queda exento de cumplir estos criterios los programas en el marco del objetivo de cooperación territorial europea. 
Tabla 3. Condiciones generales ex ante

\begin{tabular}{|c|c|}
\hline $\begin{array}{l}\text { Condiciones } \\
\text { ex ante }\end{array}$ & Criterios de cumplimiento. Disposiciones para: \\
\hline \multicolumn{2}{|c|}{ 1. Lucha contra la discriminación } \\
\hline $\begin{array}{l}\text { Legislación y } \\
\text { política UE* }\end{array}$ & $\begin{array}{l}\text { - la participación de los organismos responsables de la promoción de la igualdad de } \\
\text { trato de todas las personas. } \\
\text { - la formación del personal. }\end{array}$ \\
\hline \multicolumn{2}{|c|}{ 2. Igualdad de género } \\
\hline $\begin{array}{l}\text { Legislación y } \\
\text { política UE* }\end{array}$ & $\begin{array}{l}\text { - la participación de los organismos responsables de la igualdad de género. } \\
\text { - la formación del personal. }\end{array}$ \\
\hline \multicolumn{2}{|c|}{ 3. Discapacidad } \\
\hline $\begin{array}{l}\text { Convención } \\
\text { de la ONU } \\
\text { sobre los } \\
\text { derechos de } \\
\text { las personas } \\
\text { con } \\
\text { discapacidad* }\end{array}$ & $\begin{array}{l}\text { - la consulta y participación de los organismos responsables de la protección de los } \\
\text { derechos de las personas con discapacidad, o de las organizaciones de representa- } \\
\text { ción u otras partes interesadas pertinentes. } \\
\text { - la formación del personal. } \\
\text { - garantizar el seguimiento de la aplicación del artículo } 9 \text { de la Convención. }\end{array}$ \\
\hline \multicolumn{2}{|c|}{ 4. Contratación pública } \\
\hline $\begin{array}{l}\text { Legislación } \\
\text { UE** }\end{array}$ & $\begin{array}{l}\text { - la aplicación efectiva de las normas mediante los mecanismos adecuados. } \\
\text { - garantizar procedimientos transparentes de adjudicación de contratos. } \\
\text { - la formación y difusión. } \\
\text { - gararantizar la capacidad administrativa para su ejecución y aplicación. }\end{array}$ \\
\hline
\end{tabular}

\section{Ayudas estatales}

\begin{tabular}{ll}
\hline Legislación & - la aplicación efectiva de las normas sobre ayudas estatales. \\
UE sobre & - la formación y difusión. \\
ayudas de & - garantizar la capacidad administrativa para su ejecución y aplicación.
\end{tabular}

Estado**

6. Legislación sobre medio ambiente

\begin{tabular}{ll}
\hline Legislación & - la aplicación efectiva de la Directiva 2011/92/UE (EIA - evaluación de impacto \\
UE** & ambiental) y de la Directiva 2001/42/CE (EEM - evaluación estratégica medio- \\
& ambiental). \\
- & la formación y difusión. \\
- & garantizar una capacidad administrativa suficiente. \\
\hline
\end{tabular}

7. Sistemas estadísticos e indicadores de resultados

\begin{tabular}{ll}
\hline $\begin{array}{l}\text { Base } \\
\text { estadística. }\end{array}$ & $-\begin{array}{l}\text { Para la recopilación y agregación oportunas con los siguientes elementos: } \\
\text { - la identificación de fuentes y mecanismos para garantizar la validación estadís- } \\
\text { tica. }\end{array}$ \\
$\begin{array}{ll}\text { Sistema de } \\
\text { indicadores }\end{array}$ & $\begin{array}{l}\text { - para la publicación y puesta a disposición del público de datos agregados. } \\
\text { de resultados. }\end{array}$ \\
& Un sistema eficaz que comprende: \\
& - indicadores por programa, para justificar la selección de acciones. \\
& - el establecimiento de objetivos para estos indicadores. \\
& normativa, reactividad a la política, recopilación oportuna de los datos. \\
& Procedimientos para que en todas las operaciones financiadas por el programa se \\
& adopte un sistema de indicadores eficaz. \\
\hline
\end{tabular}

* Existencia de capacidad administrativa para la ejecución y aplicación

** Existencia de disposiciones para la aplicación efectiva

*** Existencia

Fuente: Elaboración propia. 


\subsection{ACUERDO DE ASOCIACIÓN}

En el Reglamento 1303/2013 también, se estableció la elaboración de un “Acuerdo de Asociación" por parte de cada Estado miembro para el período comprendido entre el 1 de enero de 2014 y el 31 de diciembre de 2020. Éste estará redactado tanto por los Estados miembros como por los socios (autoridades locales y otras autoridades públicas competentes, interlocutores económicos y sociales, y organismos pertinentes que representen a la sociedad civil), en diálogo con la Comisión Europea. Se incluirán todas las ayudas de los Fondos EIE.

En el acuerdo de asociación se señalarán los principales retos, los objetivos y prioridades fundamentales, los tipos de territorios que deben incluirse, el papel específico que debe atribuirse a los grupos de acción local a la hora de presentar estrategias y la función que se haya previsto para los Fondos EIE en la aplicación de las estrategias de desarrollo local participativo a los distintos territorios (zonas rurales, urbanas o litorales) de cada Estado miembro. En la Tabla 4 se resume el contenido del acuerdo a elaborar por cada Estado miembro.

Tabla 4. Contenido del Acuerdo de Asociación para el periodo 2014--2020.

\begin{tabular}{|c|c|}
\hline Apartados & Contenido \\
\hline $\begin{array}{c}\text { Medidas que } \\
\text { garanticen la } \\
\text { consonancia con la } \\
\text { estrategia Europa } 2020 \\
\text { y misiones específicas } \\
\text { de los Fondos }\end{array}$ & $\begin{array}{l}\text { - Análisis de las disparidades, las necesidades de desarrollo y el potencial } \\
\text { de crecimiento. } \\
\text { - Síntesis de las evaluaciones ex ante. } \\
\text { - Selección de objetivos temáticos } \\
\text { - Resumen de los principales resultados esperados por objetivo, en } \\
\text { relación con cada uno de los Fondos EIE. } \\
\text { - Asignación indicativa a nivel nacional: } \\
\text { - Por Fondos EIE y por objetivo temático. } \\
\text { - Para los objetivos relacionados con el cambio climático. } \\
\text { - Aplicación de principios horizontales y objetivos de actuación. } \\
\text { - Lista de los programas correspondientes a los Fondos EIE } \\
\text { - Asignaciones indicativas por Fondo y por año. } \\
\text { - Asignación a la reserva de rendimiento }\end{array}$ \\
\hline $\begin{array}{c}\text { Medidas que } \\
\text { garanticen la ejecución } \\
\text { eficaz de los Fondos } \\
\text { EIE }\end{array}$ & $\begin{array}{l}\text { - Medidas que garanticen la coordinación entre los Fondos EIE y otros } \\
\text { instrumentos de financiación. } \\
\text { - Información requerida para la verificación ex ante del cumplimiento de } \\
\text { las normas sobre adicionalidad. } \\
\text { - Resumen de la evaluación del cumplimiento de las condiciones ex ante. } \\
\text { - Metodología y los mecanismos que garanticen la coherencia en el } \\
\text { funcionamiento del marco de rendimiento. } \\
\text { - Valoración de la necesidad de reforzar la capacidad administrativa. } \\
\text { - Resumen de las acciones previstas en los programas, incluido un } \\
\text { calendario indicativo, para lograr reducir la carga administrativa de los } \\
\text { beneficiarios. }\end{array}$ \\
\hline $\begin{array}{l}\text { Medidas para el } \\
\text { principio de asociación }\end{array}$ & $\begin{array}{l}\text { - Elementos del código de conducta: para mejorar la consulta, } \\
\text { y la participación y el diálogo con los socios durante todas las fases. }\end{array}$ \\
\hline Socios del Acuerdo & - Lista indicativa de socios \\
\hline
\end{tabular}




\begin{tabular}{ccc}
\hline & $\begin{array}{l}\text { Resumen de las medidas tomadas para que los socios participen y de su } \\
\text { papel en la preparación del acuerdo de asociación y el informe de } \\
\text { evolución. }\end{array}$ \\
\hline $\begin{array}{c}\text { Enfoque integrado del } \\
\text { desarrollo territorial } \\
\text { apoyado por los }\end{array}$ & $\begin{array}{l}\text { Medidas que garanticen un enfoque integrado para zonas concretas } \\
\text { Fobregionales y zonas urbanas. }\end{array}$ \\
Fondos EIE & - Principales ámbitos prioritarios para la cooperación. \\
& Enfoque integrado para abordar las necesidades específicas de las zonas \\
& geográficas más afectadas por la pobreza o de grupos destinatarios que \\
& - Enfoque integrado para abordar los retos demográficos de las regiones o \\
& las necesidades específicas de las zonas geográficas que padecen \\
& desventajas naturales o demográficas graves y permanentes. \\
\hline $\begin{array}{c}\text { Medidas que } \\
\text { garanticen la ejecución } \\
\text { eficaz de los Fondos }\end{array}$ & - Evaluación de los sistemas existentes de intercambio electrónico de datos \\
EIE & Resumen de las acciones planificadas para total intercambio por vía \\
& electrónica.
\end{tabular}

Fuente: Elaboración propia.

En función de las directrices del Reglamento 1303/2013, el PNR, las recomendaciones específicas nacionales y del Consejo, y las evaluaciones ex ante de los programas, se evaluó la coherencia de los Acuerdos de Asociación en un plazo de tres meses. Una vez revisados y aprobados, la Comisión emitirá un informe antes de finalizar 2015 donde constarán los resultados de las negaciones del Acuerdo y de los PNR, y un resumen de las cuestiones claves para cada Estado miembro.

\subsection{PROGRAMAS DE DESARROLLO RURAL (PDR)}

Los PDR serán elaborados por los Estados miembros en colaboración con los socios, de acuerdo con las normas específicas de los Fondos EIE. Los Estados miembros podrán presentar bien un programa único para todo su territorio, bien un conjunto de programas regionales. En este último caso, deberán ser coherentes los programas regionales con el nacional, debiendo elaborar un marco nacional donde se incluirán los elementos comunes de esos programas, y teniendo en cuenta el principio de proporcionalidad.

Cada PDR definirá prioridades que establezcan objetivos específicos, créditos financieros de la ayuda de los Fondos EIE y la correspondiente cofinanciación nacional (pública o privada). A través del FEADER se financiarán los PDR para alcanzar los objetivos de desarrollo rural perseguidos a través de las prioridades de la UE. Cada prioridad irá acompañada de indicadores y objetivos (cuantitativos y cualitativos), para la evaluación de la ejecución del PDR. Los indicadores de las prioridades servirán para evaluar los avances en la ejecución del PDR de los objetivos establecidos. Se recomienda incluir indicadores financieros relativos al gasto asignado, de productividad relativos a las operaciones objeto de ayudas, y de resultados relativos a la prioridad. Además, se establecerán indicadores comunes para cada Fondo EIE en sus normas específicas y podrán establecerse disposiciones relativas a indicadores específicos de los programas. 


\section{Tabla 5. Resumen del contenido de los PDR. Apartados \\ Características/Aspectos a valorar}

Evaluación ex ante

- Contribución a la estrategia Europa 2020. Indicadores, hitos, resultados esperados, mecanismo de seguimiento y de recogida de datos.

- Adecuación de los recursos financieros, humanos y administrativos para la gestión del PDR.

- Medidas para promover la igualdad y prevenir la discriminación, para fomentar el desarrollo sostenible y, para reducir la carga administrativa de los beneficiarios.

\begin{tabular}{|c|c|}
\hline $\begin{array}{l}\text { Matriz DAFO e identifica- } \\
\text { ción de necesidades }\end{array}$ & $\begin{array}{l}\text { DAFO de la situación actual } \\
\text { - } \quad \text { Determinación de las necesidades de la zona geográfica } \\
\text { - Basadas en las prioridades de desarrollo rural }\end{array}$ \\
\hline $\begin{array}{l}\text { Estrategia sobre la contri- } \\
\text { bución del PDR a la } \\
\text { Estrategia } 2020\end{array}$ & $\begin{array}{l}\text { - Disposiciones que garanticen la ejecución efectiva, eficiente y coordi- } \\
\text { nada de los Fondos EIE. } \\
\text { - Acciones dirigidas a reducir la carga administrativa. }\end{array}$ \\
\hline Prioridades & $\begin{array}{l}\text { - Que establezcan: indicadores y objetivos específicos (cuantitativos y } \\
\text { cualitativos), créditos financieros de la ayuda de los Fondos EIE y cofi- } \\
\text { nanciación nacional, importes de la reserva de rendimiento. }\end{array}$ \\
\hline $\begin{array}{l}\text { Evaluación de las condi- } \\
\text { cionalidades ex-ante }\end{array}$ & $\begin{array}{l}\text { - Evaluación de aquellas que son aplicables al PDR y que se cumplen en } \\
\text { la fecha de presentación del Acuerdo de Asociación y del PDR. } \\
\text { - Acciones y calendario para alcanzar las condiciones que no se cumplan. }\end{array}$ \\
\hline $\begin{array}{l}\text { Descripción del marco de } \\
\text { rendimiento }\end{array}$ & $\begin{array}{l}\text { - Hitos establecidos para cada prioridad, para el año 2018, y las metas } \\
\text { establecidas para } 2023 \text {. }\end{array}$ \\
\hline $\begin{array}{l}\text { Descripción de las medidas } \\
\text { seleccionadas }\end{array}$ & $\begin{array}{l}\text { - De acuerdo con las medidas de especial interés para las prioridades, } \\
\text { recogidas en el Capítulo I del Título III del Reglamento } 1505 / 2013 \text {. }\end{array}$ \\
\hline Plan de evaluación & $\begin{array}{l}\text { - Evaluará cómo los Fondos EIE ha contribuido a los objetivos de cada } \\
\text { prioridad }\end{array}$ \\
\hline Plan de financiación & $\begin{array}{l}\text { - Cuadro con la contribución total del FEADER por año. } \\
\text { - Cuadro con la contribución del FEADER por medida. }\end{array}$ \\
\hline Plan de indicadores & $\begin{array}{l}\text { - Desglosado en ámbitos de interés, junto con los objetivos establecidos, } \\
\text { los resultados esperados y los gastos previstos de cada medida. }\end{array}$ \\
\hline $\begin{array}{l}\text { Financiación } \\
\text { suplementar }\end{array}$ & - Por medida seleccionada. \\
\hline $\begin{array}{l}\text { Evaluación de ayudas de } \\
\text { estado }\end{array}$ & $\begin{array}{l}\text { - Para las medidas financiadas a través de los demás instrumentos de la } \\
\text { PAC y de los Fondos EIE. }\end{array}$ \\
\hline $\begin{array}{l}\text { Información sobre com- } \\
\text { plementariedad }\end{array}$ & $\begin{array}{l}\text { - Lista de los regímenes de ayuda a los que se vaya a recurrir para ejecu- } \\
\text { tar los PDR. }\end{array}$ \\
\hline $\begin{array}{l}\text { Disposiciones de aplica- } \\
\text { ción del programa }\end{array}$ & $\begin{array}{l}\text { - Estructura de gestión y control, autoridades designadas. } \\
\text { - Descripción de los sistemas de seguimiento y evaluación y Comité de } \\
\text { seguimiento. } \\
\text { - Disposiciones para dar publicidad al PDR. } \\
\text { - Principios para los criterios de selección de las operaciones y a las } \\
\text { estrategias de desarrollo. }\end{array}$ \\
\hline $\begin{array}{l}\text { Acciones para involucrar a } \\
\text { los agentes }\end{array}$ & $\begin{array}{l}\text { - Lista de acciones para involucrar a los agentes } \\
\text { - Resumen de los resultados de las consultas a los interlocutores }\end{array}$ \\
\hline Red rural nacional & $\begin{array}{l}\text { - Estructura de la red. } \\
\text { - Disposiciones para su gestión. }\end{array}$ \\
\hline Subprogramas temáticos & $\begin{array}{l}\text { - Análisis DAFO e identificación de necesidades, objetivos específicos y } \\
\text { medidas, indicadores, resultados previstos y gastos previstos. }\end{array}$ \\
\hline
\end{tabular}


En los PDR se podrán incluir subprogramas temáticos relacionados principalmente con: los jóvenes agricultores, las pequeñas explotaciones agrícolas, las zonas de montaña, las cadenas de distribución cortas, las mujeres de las zonas rurales, la mitigación del cambio climático y la adaptación a este, así como la biodiversidad, y las necesidades específicas ligadas a la reestructuración de sectores agrícolas de importancia para el desarrollo de una zona rural. Los PDR contendrán la información resumida en la Tabla 5.

Tanto en la evaluación ex ante, como en la estrategia sobre la contribución del PDR a la Estrategia 2020, se evaluará la coherencia interna del PDR, con los Fondos EIE, con el MEC, con el Acuerdo de Asociación y con las recomendaciones específicas de la Comisión. La descripción de las medidas seleccionadas y el plan de evaluación se elaborarán de acuerdo con las normas específicas de los Fondos EIE. Los PDR que prevean exclusivamente asistencia técnica no deberán realizar descripción de las medidas.

\subsection{MEDIDAS DEL DESARROLLO RURAL FINANCIADAS POR EL FEADER}

Figura 8. Subprogramas temáticos y medidas de especial relevancia.

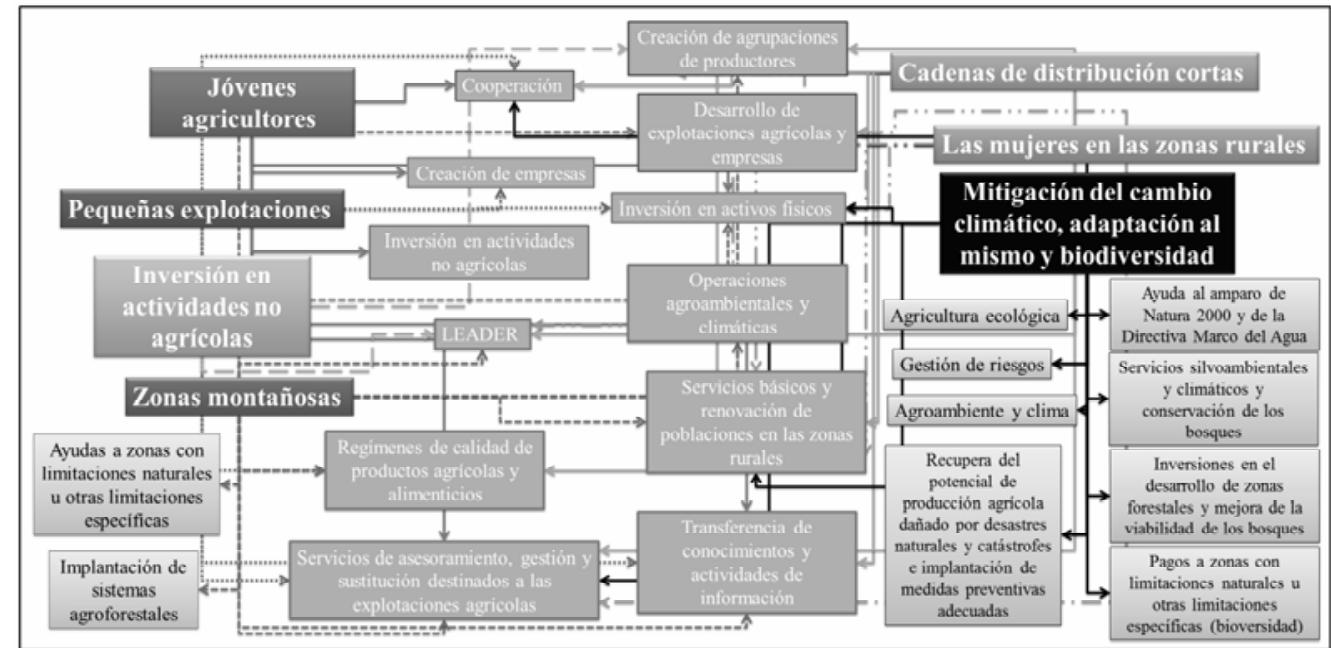

Fuente: Elaboración propia.

En el Reglamento 1505/2013 se establecen las medidas de los siete subprogramas temáticos en las que se articulará el Desarrollo Rural en el periodo 2014-2020 (Figura 8). Para su aplicación, la Comisión adoptará actos de ejecución para establecer normas en relación con: la selección de autoridades u organismos que ofrecerán servicios de asesoramiento agroforestal, de gestión de las explotaciones o de sustitución en la explotación; la evaluación de los progresos de planes y gestión de ayudas al desarrollo de explotaciones agrícolas y empresas; homogenización de unidades ganaderas; el cálculo normalizado de pérdidas de ingresos y costes 
adicionales por los compromisos medioambientales adquiridos; $\mathrm{y}$, el cálculo del importe de la ayuda cuando una operación sea subvencionable al amparo de más de una medida.

A continuación se resumen las principales características de las distintas medidas propuestas por la UE, que deberán ser adaptadas a las necesidades y requerimientos de cada Estado miembro. La medida LEADER será analizada en el siguiente apartado.

\section{1) Medidas de carácter agrícola}

La transferencia de conocimientos y actividades de información incluye actividades de formación profesional y adquisición de competencias (cursos de formación, talleres y sesiones de orientación, intercambios cortos, visitas técnicas). Está dirigida a gestores, profesionales y empresarios (pymes) de las zonas rurales, en los sectores agrario, alimentario y forestal.

Los servicios de asesoramiento, gestión y sustitución de explotaciones agrarias se enfocarán principalmente en jóvenes agricultores, gestores de tierras y pymes. Se promoverá también la formación de asesores para el medio rural. Los servicios se orientarán a incrementar los resultados económicos, el cuidado medioambiental y la adaptación al cambio climático.

En relación con los regímenes de calidad de los productos agrícolas y alimenticios, los principales beneficiarios serán los agricultores y agrupaciones de agricultores que participen por primera vez en certificación de: denominaciones de origen, indicaciones geográficas protegidas, especialidades tradicionales garantizadas, productos ecológicos, indicación geográfica de bebidas espirituosas, vinos aromatizados, de bebidas aromatizadas a base de vino y de cócteles aromatizados de productos vitivinícolas, vinos, y de productos con calidades superiores a las normas comerciales.

La inversión en activos físicos (materiales o inmateriales) buscan mejorar el rendimiento global y la sostenibilidad de la explotación agrícola; promover la transformación, comercialización o desarrollo de los productos agrícolas; fomentar las infraestructuras destinadas al desarrollo, modernización o adaptación de la agricultura y el sector forestal, apoyar inversiones no productivas relacionadas con los objetivos agroambientales, de conservación y de utilidad pública de zonas de la red Natura 2000.

Las acciones financiadas dentro la medida de reconstitución del potencial de producción agrícola dañado por desastres naturales y catástrofes e implantación de medidas preventivas adecuadas, financiarán únicamente inversiones de carácter preventivo y de recuperación.

El desarrollo de explotaciones agrícolas y empresas se enfocará en la creación de empresas por jóvenes agricultores (previa presentación de plan empresarial), para actividades no agrícolas, y para el desarrollo de pequeñas explotaciones. También, para la creación y el desarrollo de actividades no agrícolas, y en pagos anuales para agricultores que cedan de forma permanente su explotación a otro agricultor. 


\section{2) Medidas de carácter forestal}

Operaciones de reforestación, implantación de sistemas agroforestales, remediación de bosques, mejora de los ecosistemas forestales y las inversiones en tecnologías forestales (toda la cadena productiva) serán objeto de financiación dentro de la medida de inversiones en el desarrollo de zonas forestales y mejora de la viabilidad de los bosques.

Las zonas susceptibles de financiación dentro de la medida de reforestación y creación de superficies forestales podrán ser tanto agrícolas como con otros usos, y públicas o privadas. Se cubrirán los costes de establecimiento y una prima anual por hectárea para cubrir pérdidas por cambio de actividad y costes de mantenimiento (máximo 12 años). Deberán utilizarse especies adaptadas a cada zona, y se excluyen especies para la producción de energía.

En la implantación de sistemas agroforestales (forestales + agricultura) se financiarán los costes de implantación y una prima anual por hectárea para cubrir costes de mantenimiento (máximo 5 años).

Para la prevención y reparación de los daños causados a los bosques por incendios, desastres naturales y catástrofes, se financiarán infraestructuras de protección, actividades locales de prevención a pequeña escala, implantación y mejora de instalaciones de vigilancia, y operaciones de restauración. Las operaciones serán compatibles con el Plan nacional de protección forestal.

Las inversiones para incrementar la capacidad de adaptación y el valor medioambiental de los ecosistemas forestales se destinarán al cumplimiento de los compromisos con objetivos medioambientales y de provisión de servicios de los ecosistemas (utilidad pública potencial de mitigación del cambio climático).

Las inversiones en tecnologías forestales y en la transformación, movilización y comercialización de productos forestales podrán incluir compra de maquinaria y mejora de las prácticas de explotación forestal respetuosas con el suelo y los recursos. Se financiarán actividades anteriores a la transformación industrial en el caso de producción de energía.

Se financiará la creación de agrupaciones y organizaciones de productores en los sectores de la agricultura y la silvicultura para la comercialización conjunta de los productos, la adaptación y mejora del rendimiento de acuerdo con las exigencias del mercado, el establecimiento de normas comunes relativas a la información sobre la producción, el desarrollo de competencias empresariales y comerciales, y la organización y facilitación de procesos innovadores. Las agrupaciones y organizaciones deberán ser reconocidas por los Estados miembros como pymes.

\section{3) Medidas de carácter medioambiental}

La medida de agroambiente y clima es de obligada inclusión en los PDR, y estará dirigida tanto al mantenimiento como a la promoción de los cambios necesarios en las prácticas agrícolas que contribuyan positivamente al medio ambiente y al clima, y que son superiores a las mejoras obligatorias. Se excluye la implantación de la agricultura 
ecológica. El compromiso por parte de los agricultores será voluntario, debiendo ser informados y asesorados adecuadamente.

Para la promoción de la agricultura ecológica, la ejecución de operaciones en favor del bienestar de los animales y la realización de servicios silvoambientales y climáticos y conservación de los bosques, se financiarán compromisos voluntarios de agricultores activos, siempre que las exigencias sean mayores a las normas obligatorias. Los bosques estatales únicamente recibirán ayudas cuando son gestionados por municipios u organismos privados.

Los pagos al amparo de Natura 2000 y de la Directiva Marco del Agua tienen como objetivo compensar su aplicación cuando los requisitos son más estrictos que las buenas condiciones agrarias y medioambientales previstas en el Reglamento $1306 / 2013$.

En estas medidas se compensarán las pérdidas y costes adicionales como consecuencia de los compromisos adquiridos. También se podrá abarcar los costes de transacción hasta un máximo del $20 \%$ de la prima abonada por los compromisos adquiridos.

La ayuda a zonas con limitaciones naturales (de montaña) $u$ otras limitaciones específicas compensará la totalidad o una parte de los costes adicionales y las pérdidas de ingresos como consecuencia de las limitaciones que supone la producción agrícola en estas zonas. Los Estados miembros deben designar previamente, en los $\mathrm{PDR}$, las zonas con limitaciones naturales u otras limitaciones específicas en función de tres categorías: a) zonas de montaña, b) zonas distintas de las de montaña con limitaciones naturales significativas, y c) otras zonas con limitaciones específicas;

a) Las zonas de montaña se caracterizan por una limitación considerable del uso de la tierra y el aumento de costes de producción cuando existe: una reducción notable del periodo vegetativo por la altitud y las condiciones climáticas rigurosas, dificultad de trabajar la tierra con maquinaria por pendientes demasiado pronunciadas $y / o$ que requieren maquinaria especial costosa.

b) Las zonas distintas de las de montaña presentan limitaciones naturales significativas de clima y suelo en al menos el $60 \%$ de su superficie agrícola de acuerdo con los criterios enumerados en el anexo III del Reglamento $1305 / 2013$.

c) Las zonas afectadas por limitaciones específicas recibirán ayudas cuando deba mantenerse en ellas la gestión de las tierras para preservar o mejorar el medio ambiente, conservar el medio rural y preservar el potencial turístico de la zona o para proteger el litoral.

Las zonas distintas de las de montaña y con limitaciones específicas deberán estar a escala LAU 2 o a escala de una unidad local claramente delimitada que cubra una única zona geográfica contigua, dotada de una identidad económica y administrativa claramente definible. 


\section{4) Medidas de carácter transversal}

La medida de servicios básicos y renovación de poblaciones en las zonas rurales comprende ayudas para la elaboración y actualización de planes municipales de desarrollo y, de protección y gestión de zonas naturales (red Natura 2000 y otras); pequeñas infraestructuras (energías renovables y eficiencia energética); infraestructuras y oferta de banda ancha; administración pública electrónica; creación, mejora o ampliación de servicios básicos; infraestructuras públicas recreativas y turísticas a pequeña escala; patrimonio cultural y natural de las poblaciones; el traslado de actividades y la transformación de edificios para la mejora medioambiental.

La ayuda en el marco de la Cooperación se concederá para fomentar formas de cooperación entre al menos dos entidades (de una misma o diferente región o Estado miembro) de los sectores agrario, forestal y de la cadena alimentaria (agentes, agrupaciones de productores, cooperativas y organizaciones interprofesionales), para promover la creación de grupos y redes, y la creación y el funcionamiento de grupos operativos de la Asociación Europea para la Innovación (AEI) en materia de productividad y sostenibilidad agrícolas. La cooperación abarcará distintos aspectos: proyectos piloto, innovación en toda las fases de producción, comercialización y distribución, trabajo/producción coordinado, actividades de promoción, acción conjunta para la mitigación o adaptación al cambio climático, proyectos y prácticas medioambientales, planes de gestión forestal o equivalente, y la diversificación de actividades agrarias en actividades relacionadas con la atención sanitaria, la integración social, la agricultura respaldada por la comunidad y la educación sobre el medio ambiente y la alimentación. Se financiarán los costes de estudios de viabilidad, de elaboración de planes, de actividades de animación, de funcionamiento y de promoción.

\section{5) Medidas de carácter financiero}

Para la gestión del riesgo se financiarán las contribuciones financieras a las primas del seguro de cosechas, animales y plantas, y a fondos mutuales para el pago de compensaciones financieras, a los agricultores por las pérdidas económicas causadas por adversidades climáticas, el brote de una enfermedad animal o vegetal o de una infestación por plagas, o un incidente medioambiental. También la financiación de un instrumento de estabilización de los ingresos consistente en contribuciones financieras a fondos mutuales que ofrezcan compensación a los agricultores por una acusada disminución de sus ingresos.

Los seguros y el instrumento financiero serán objeto de ayuda cuando se haya destruido más del $30 \%$ de la producción anual media del agricultor en el trienio anterior o de su producción media trienal respecto del período quinquenal anterior, excluidos los valores más alto y más bajo. 


\section{6) Disposiciones comunes a varias medidas}

En las medidas relacionadas con los daños causados por desastres naturales, los Estados miembros deberán reconocer oficialmente como tal la situación, para financiar y ejecutar las acciones. En ningún caso se financiarán pérdidas económicas por desastres naturales o catástrofes.

Las operaciones de inversión deberán ir precedidas de una evaluación del impacto medioambiental, si existiese la probabilidad de efectos negativos. Serán subvencionables, a cargo del FEADER, gastos como: construcción, adquisición o mejora de bienes inmuebles, compra o arrendamiento de nueva maquinaria y equipo, honorarios de técnicos y asesores, y compra de intangibles (programas informáticos, patentes agrícolas, derechos de ayuda, animales, plantas anuales y su plantación).

En el caso de las instalaciones de riego en superficies de regadío nuevas o existentes, únicamente se considerarán gastos subvencionables las inversiones que cumplan las siguientes condiciones: notificación de plan hidrológico de demarcación, haberse instalado o irse a instalar un sistema de medición del uso de agua correspondiente a la inversión objeto de la ayuda, evaluación del ahorro potencial de agua (5-25\%) en casos de mejora de instalaciones o infraestructuras existentes, o incremento neto de la superficie irrigada (determinados casos).

En relación con las ayudas por superficie, el número de hectáreas a las que se aplica un podrá variar de un año a otro cuando así se ha establecido en el PDR, cuando el compromiso en cuestión no se aplica a parcelas fijas, y cuando no se compromete el logro del objetivo del compromiso. La ejecución del compromiso podrá mantenerse si existiese transferencia total o parcial de la explotación si el nuevo propietario desea continuar con el mismo. Si el beneficiario no puede asumir los compromisos por cambios en el ordenamiento territorial, Los Estados miembros deberán adaptar el compromiso a la nueva situación, o si no es posible continuar, se dará por terminado. No existirá reembolso por el periodo durante el cual el compromiso fue efectivo, ni en casos de fuerza mayor o excepcionales.

Si los compromisos medioambientales se volvieren más estrictos, se podrá aplicar una cláusula de revisión de las operaciones. Si el beneficiario no acepta la adaptación, se dará por finalizado el compromiso, sin posibilidad de reembolso.

Los criterios de selección de las operaciones serán establecidos por la autoridad de gestión del PDR, previa consulta al comité de seguimiento. Éstos deberán garantizar un trato equitativo, un uso más satisfactorio de los recursos financieros y la orientación de las medidas hacia las prioridades de desarrollo rural de la UE. Los criterios de selección se elaborarán y aplicarán atendiendo al principio de proporcionalidad en relación con el tamaño de la operación. 3. Cuando proceda, los beneficiarios podrán ser seleccionados mediante convocatorias de propuestas, en las que se aplicarán criterios de eficiencia económica y medioambiental. 


\section{7) Asistencia técnica y creación de redes}

Se establece que hasta el $0.25 \%$ anual de los fondos del FEADER se podrá destinar a asistencia técnica por iniciativa de la Comisión. Las tareas subvencionables están relacionadas con las medidas de preparación, seguimiento, asistencia técnica y administrativa (refuerzo institucional y generación de capacidades administrativas), evaluación, auditoría, control, gestión e intercambio de información y buenas prácticas (incluido su informatización). También se incluyen los costes de creación y funcionamiento de la red europea de desarrollo rural y de la red de AEI. El porcentaje podrá incrementarse hasta un $4 \%$ para acciones relacionadas con la reducción de la carga administrativa de los beneficiarios, el refuerzo de la capacidad de los socios, el apoyo al intercambio de buenas prácticas, y los costes derivados de la labor preparatoria de delimitación de las zonas con limitaciones naturales u otras limitaciones específicas. Dentro del límite máximo del $4 \%$, se reservará un importe para la creación y el funcionamiento de la red rural nacional.

La red europea de desarrollo rural busca la conexión de las redes, organizaciones y administraciones que están activas en el sector del desarrollo rural a escala de la UE.

Los objetivos de esta red son:

- Impulsar una mayor participación de todas las partes interesadas, y en particular de los sectores agrícola, forestal y otras partes interesadas del desarrollo rural, en la aplicación de la política de desarrollo rural;

- mejorar la calidad y apoya la evaluación de los PDR;

- informar al público en general de los beneficios derivados de la política de desarrollo rural.

Entre las tareas de la red destaca: la gestión y divulgación de la información sobre la actuación en el ámbito del desarrollo rural y de las buenas prácticas de desarrollo rural, ofrecer apoyo a los procesos de evaluación y a la recopilación y gestión de datos, organizar reuniones y seminarios a escala europea, prestar apoyo a las redes nacionales, a las iniciativas de cooperación transnacional y al intercambio sobre actuaciones y experiencias con redes de terceros países, cooperar con otros organismos relacionados creados por los Fondos EIE, entre otras.

La red AEI prestará a poyo a la AEI en materia de productividad y sostenibilidad agrícolas haciendo posible la conexión de los grupos operativos, los servicios de asesoramiento y los investigadores. Sus tareas se enfocarán en prestar ayuda y facilitar información sobre la AEI a los principales agentes, fomentar la creación de grupos operativos, facilitar el planteamiento de iniciativas de grupos y de proyectos piloto o de demostración, y recopilar y divulgar información. A través de las actividades de la red se busca facilitar el intercambio de experiencia y buenas practicas, y establecer un diálogo entre los agricultores y el mundo de la investigación y facilitar la inclusión de todos los interlocutores interesados en el proceso de intercambio de conocimientos. 
La red rural nacional integra a las organizaciones y administraciones participantes en el desarrollo rural. Se financiará a través del FEADER: las estructuras necesarias para dirigir la red, y la elaboración y ejecución de un plan de acción. Éste recogerá como mínimo: las actividades relativas a la recopilación de ejemplos de proyectos que abarquen todas las prioridades de los PDR, las actividades relativas a la facilitación de intercambios temáticos y analíticos e intercambio y divulgación de los resultados y de las conclusiones del seguimiento y la evaluación, las actividades relativas a la facilitación de formación y de una red de contactos para los GAL (principalmente dar asistencia técnica a la cooperación interterritorial y transnacional), un plan de comunicación con publicidad e información sobre el PDR, y las actividades relativas a participar en la red europea de desarrollo rural y contribuir a las mismas.

\subsection{DESARROLLO LOCAL PARTICIPATIVO Y LEADER}

El desarrollo local participativo (DLP) o desarrollo local Leader será financiado por los Fondos EIE: FEDER, FSE y/o FEMP (solo por uno o en combinación), centrando su actividad en zonas subregionales concretas a través de los grupos de acción local (GAL), cuyas características son similares a las del periodo 2007-2013. Se realizarán mediante estrategias de desarrollo local integradas, multisectoriales y basadas en zonas, basando su diseño en las necesidades y potencial locales, la innovación, el establecimiento de redes y la cooperación (opcional).

Las Estrategias de desarrollo local participativo (EDLP) serán elaboradas y ejecutadas por los GAL, cuyo papel será definido por cada Estado miembro. Deberán, como mínimo, contener los siete elementos recogidos en la Figura 9. Serán seleccionadas por un comité nacional de acuerdo con los criterios definidos por cada Estado miembro. Las EDLP se ejecutarán en zonas cuya población sea mayor a 10.000 y menor a 150.000 habitantes, pudiendo aplicarse en zonas con menor o mayor población siempre que se justifique por su carácter de zonas escasa o densamente pobladas.

Los GAL deberán designar o bien un socio principal o adoptar una estructura común legalmente constituida a efectos de representación en los asuntos administrativos y financieros. Las tareas de los GAL son:

a) generar la capacidad de los agentes locales para desarrollar y llevar a la práctica las operaciones, también fomentando sus capacidades de gestión de proyectos;

b) diseñar un procedimiento no discriminatorio y transparente de selección y criterios objetivos de selección de las operaciones que eviten conflictos de intereses (el GAL si podrá ser beneficiario), garanticen que por lo menos el $50 \%$ de los votos en las decisiones de selección provengan de socios que no sean autoridades públicas, y permitan efectuar la selección por procedimiento escrito; 
c) garantizar la coherencia con la EDLP al seleccionar las operaciones, ordenándolas por prioridades según su contribución a la consecución de sus objetivos y metas;

d) preparar y publicar convocatorias de propuestas o un procedimiento continuo de presentación de proyectos, inclusive definiendo los criterios de selección;

e) recibir las solicitudes de ayuda y evaluarlas;

f) seleccionar las operaciones, fijar el importe de la ayuda y, cuando proceda, presentar las propuestas al organismo responsable de la verificación final de la subvencionabilidad antes de la aprobación;

g) hacer un seguimiento de la puesta en práctica de la EDLP y de las operaciones subvencionadas y llevar a cabo actividades de evaluación específicas vinculadas a esa estrategia;

h) desempeñar tareas suplementarias delegadas en ellos por la autoridad de gestión o el organismo pagador.

Figura 9. Elementos básicos de las estrategias de desarrollo local participativo.

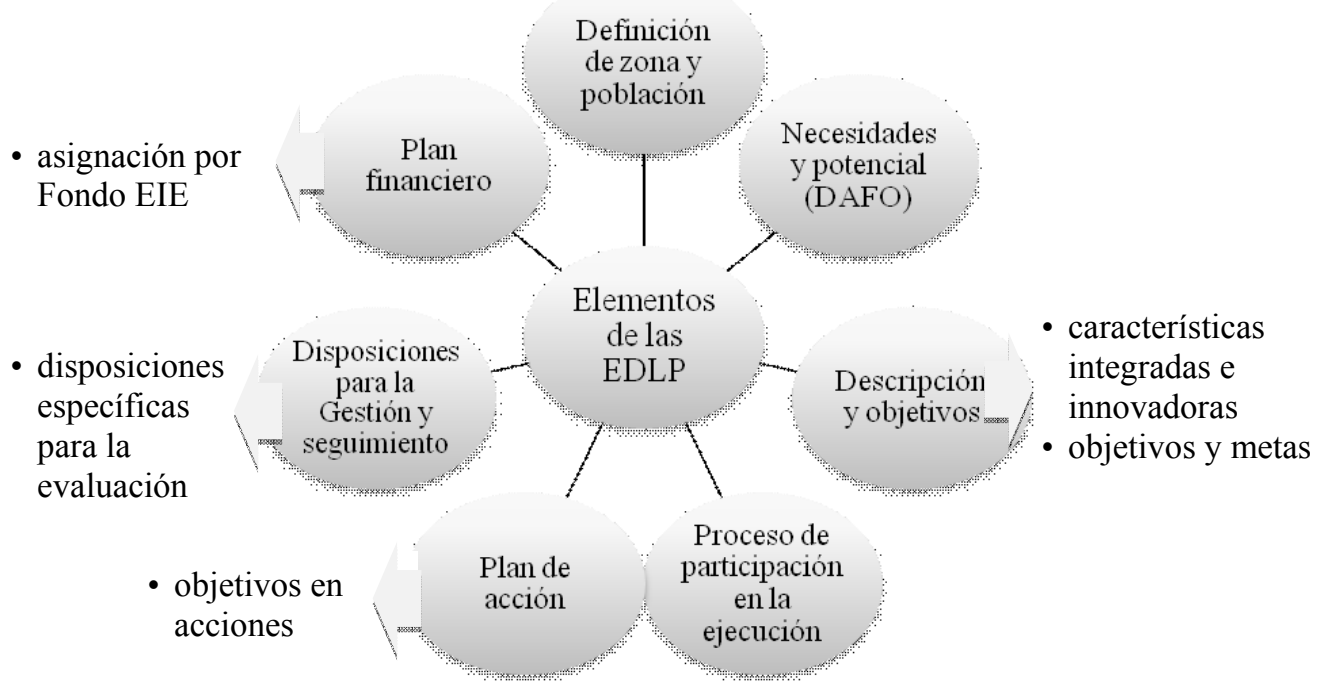

Fuente: Elaboración propia.

La ayuda de los Fondos EIE incluirá los costes de la ayuda preparatoria (estudios, formación, elaboración de la EDLP, costes administrativos, y proyectos pilotos) independientemente de que se subvencione o no posteriormente la EDLP, la realización de las operaciones conforme a la EDLP, la preparación y realización de las actividades de cooperación del GAL, los costes de explotación vinculados a la gestión de la puesta en práctica de la EDLP (funcionamiento, de personal, de formación, relaciones públicas, financieros, la supervisión y evaluación), y la 
animación de la EDLP con el fin de facilitar el intercambio entre las partes interesadas para suministrar información y fomentar la estrategia y para apoyar a los beneficiarios potenciales con vistas a desarrollar operaciones y preparar solicitudes. Los costes de explotación y para animación no superarán el $25 \%$ del gasto público total de la EDLP

Aquellas zonas que no hayan aplicado Leader en el período 2007-2013 podrán recibir ayuda para actividades de capacitación y para pequeños proyectos piloto, en el marco del "kit de puesta en marcha de Leader", sin necesidad de presentar una EDLP.

Las actividades de cooperación se financiarán para proyectos de cooperación interterritorial y transnacional (UE o terceros países) y asistencia técnica preparatoria de proyectos. En este caso, también podrán ser socios públicos o privados, organismos fuera de la UE o dentro de un territorio europeo que no aplique una EDLP.

Las acciones podrán realizarse como Inversión territorial integrada (ITI) cuando una estrategia de desarrollo urbano u otra estrategia territorial, o un pacto territorial, exijan un enfoque integrado que implique inversiones del FSE, el FEDER o el FC conforme a más de un eje prioritario de uno o varios programas operativos. Estas acciones también podrán financiarse con el FEADER y el FEMP. La gestión y ejecución de ITI podrá estar a cargo de autoridades locales, organismos de desarrollo regional u organizaciones no gubernamentales, designados por el Estado miembro.

\subsection{SEGUIMIENTO Y EVALUACIÓN}

La Comisión Europea y los Estados miembros colaborarán en la creación de un sistema común de seguimiento y evaluación para demostrar los avances y logros de la política de desarrollo rural y analizar la repercusión, la eficacia, la eficiencia y la pertinencia de sus intervenciones; contribuir a orientar con mayor precisión las ayudas; y, apoyar un proceso de aprendizaje común en materia de seguimiento y evaluación.

Para realizar el seguimiento y evaluación se implementarán tres instrumentos: una lista de indicadores comunes, un sistema electrónico de información y una base de datos con la información suministrada por los beneficiarios.

La lista de indicadores comunes permitirá la agregación de los datos a escala de la UE. Los indicadores harán referencia a la situación inicial, la ejecución financiera, las realizaciones, los resultados y el impacto de cada PDR. Los indicadores comunes de impacto se basarán en datos disponibles, y permitirán al evaluador cuantificar la incidencia del PDR. En el sistema electrónico de información se registrarán y mantendrán los datos esenciales de la ejecución del PDR y de las operaciones financiadas y ejecutadas. Beneficiarios y GAL deberán proporcionar toda la información necesaria para poder realizar el seguimiento y la evaluación del programa, en particular en relación con el cumplimiento de determinados objetivos y prioridades.

La autoridad de gestión y el comité nacional de seguimiento realizarán el seguimiento de cada PDR a través de indicadores financieros, de realización y de objetivos, elaborando un informe anual sobre la ejecución del programa. La 
evaluación ex ante y ex post se realizará cumpliendo con los requisitos mínimos (planteamiento común de evaluación) establecidos por la Comisión.

\section{DESARROLLO DE LA NORMATIVA EUROPEA EN ESPAÑA}

Para el desarrollo de la normativa, España ha tomado, hasta la fecha, las siguientes decisiones:

- Elaborar el Acuerdo de Asociación 2014-2020, el cual fue enviado oficialmente a la Comisión Europea el 22 de abril de 2014.

- Elaborar el Marco Nacional de Desarrollo Rural consensuado entre las CC.AA. y la Sociedad civil organizada relacionada con el desarrollo rural, para incorporar elementos comunes y medidas horizontales para programas de Desarrollo Rural regionales que se establecerán, uno por CC.AA., acordes con el marco competencial español. El proceso de participación pública, como requiere el reglamento, se realizó, a través de la Red Rural Nacional, entre el 6 y el 26 de mayo de 2014. Se envió oficialmente a la Comisión Europea el 4 de julio de 2014.

- Elaborar el Programa Nacional de Desarrollo Rural 2014-2020, coherente con los diecisiete PDR regionales. La autoridad de gestión del PNDR es el Ministerio de Agricultura, Alimentación y Medio Ambiente, a través de la Dirección General de Desarrollo Rural y Política Forestal. Se presentó a la Comisión Europea el 21 de julio, y actualmente está en fase de información pública y consultas dentro del proceso de Evaluación Estratégica Ambiental.

Hay que considerar que de los cinco Fondos EIE, solo se aplicarán cuatro en España en el periodo de programación 2014-2020 (FEDER, FSE, FEMP y FEADER). El FC ya no será de aplicación en este nuevo periodo en territorio español.

\subsection{ACUERDO DE ASOCIACIÓN}

En el Acuerdo de Asociación 2014-2020 se identificó la necesidad de incrementar la productividad y la competitividad y promover el empleo en un marco de consolidación fiscal y de restricción del crédito, como el principal reto del modelo socio económico español. Para solventar esta necesidad se han marcado los siguientes objetivos:

- Optimizar el impacto de las actuaciones cofinanciadas.

- Impulsar los sectores con elevado potencial de crecimiento.

- Explotar sinergias entre Fondos, así como con otras políticas e instrumentos de la UE.

- Contribuir a impulsar las reformas definidas en España para superar la crisis, especialmente las orientadas al empleo, la productividad y la competitividad.

- Apoyar los instrumentos financieros y la inversión privada con el fin de lograr un efecto multiplicador de los recursos públicos. 
Tabla 6. Matriz DAFO del análisis de disparidades. FORTALEZAS

- Mejora de la competitividad española a través de las reformas y la reducción de costes salariales.

- Capital humano cualificado y competitivo.

- Recuperación de sectores estratégicos (turismo).

- Mejora de la balanza por cuenta corriente. Aumento y diversificación de las exportaciones.

- Importante aumento de los niveles de internacionalización de las empresas españolas. Mejora de la balanza comercial y por cuenta corriente.

- Fortalecimiento del Sistema de Ciencia y Tecnología en las dos últimas décadas.

- Altos niveles de penetración de las TIC en las empresas y en la ciudadanía.

- Especialización sectorial (turismo, agroalimentario, construcción, energías renovables...).

- Aumento de las tasa de actividad femenina en las últimas dos décadas.

- Desarrollo e integración de las energías renovables en el sistema energético.
- Reformas estructurales en múltiples ámbitos para relanzar la competitividad de la economía española.

- Esfuerzos de consolidación fiscal para eliminar los desequilibrios macroeconómicos y las tensiones financieras.

- Recapitalización y reestructuración del sector bancario para sanear el sector, restablecer el crédito y animar la inversión productiva.

- Reforma de las Administraciones públicas (Comisión para la Reforma de las Administraciones Públicas-CORA).

- Reforma de la Administración Local.

- Reforma del mercado de trabajo.

- Renovación del tejido productivo ligada a la propia crisis económica.

- Apoyo a la iniciativa empresarial y al crecimiento de proyectos empresariales.

- Reforma energética para garantizar la sostenibilidad económica y financiera del sistema.

- Mayor predisposición al emprendimiento entre la ciudadanía y más medidas de apoyo.

\section{DEBILIDADES}

AMENAZAS

- Elevadas tasas de desempleo, en especial, de desempleo juvenil.

- Contracción del PIB hasta situarse por debajo de la media de la UE.

- Elevado déficit acumulado.

- Alto nivel de endeudamiento de las familias, empresas y Administraciones.

- Restricción del crédito a las familias y empresas

- Aumento de la vulnerabilidad de grandes grupos de población (desempleo de larga duración, deterioro de condiciones laborales de algunos colectivos)

- Sistema educativo con niveles de calidad inferiores a la media de los países del entorno.

- Productividad de las PYME (especialmente de las microempresas) muy baja en términos comparados.

- Alta tasa de mortalidad de nuevas empresas (sistema de emprendimiento poco profesionalizado-emprendimiento por necesidad, programas de apoyo insuficientes o poco eficaces)

- Escasa transferencia de conocimiento en el Sistema de Ciencia y Tecnología nacional.

- Importante caída de la propensión innovadora de las PYMES en período de crisis, tanto en innovación organizativa y comercial como, especialmente, en innovación tecnológica.

Fuente: Elaboración propia. 
Cumpliendo con el reglamento, se han clasificado las regiones españolas en función de su PIB: más desarrolladas con PIB > 90\% del PIB de la media de la UE (Galicia, Asturias, Cantabria, País Vasco, Navarra, La Rioja, Aragón, Cataluña, Castilla y León, Madrid y Comunidad Valenciana), en transición con PIB entre 75 y 90\% (Castilla La Mancha, Murcia y Andalucía) y, menos desarrolladas con un PIB < $75 \%$ (Extremadura).

El análisis de las disparidades, las necesidades de desarrollo y el potencial de crecimiento de la economía y el modelo productivo español dio como resultado la matriz DAFO (Tabla 6). En relación con el cumplimiento de las condiciones ex ante, se señala que España debe aún justificar las condiciones ex ante temáticas FEDER y FSE, relacionadas con la prevención de riesgos y la gestión de riesgos, y las del sector residuos; y las condiciones ex ante generales del FEDER, FSE y FEADER, relacionadas con los sistemas estadísticos e indicadores de resultado.

España ha seleccionado los once objetivos temáticos propuestos, pero dará especial énfasis a: investigación e innovación, desarrollo de infraestructuras y servicios TIC, desarrollo de las pymes y fomento de una economía baja en carbono. En la Tabla 7 se recogen los principales resultados esperados y, los indicadores y metas que permitirán la evaluación y seguimiento. La asignación de los fondos del FEADER para los objetivos temáticos (excluido OT11) es de $17972092126 €$ para el periodo 2014-2020. De este monto, aproximadamente el 93\% irá destinado a seis objetivos temáticos $(24.10 \%$ a OT1, $10.74 \%$ a OT2, $16.02 \%$ a OT3, $17.30 \%$ a OT4, $10.35 \%$ a OT6 y $14.64 \%$ a OT7). No se indica en el Acuerdo de Asociación las asignaciones para los objetivos relacionados con el cambio climático.

La coordinación entre los fondos EIE con otras Políticas de la UE se realizará mediante las siguientes estructuras: Comité de Coordinación de Fondos EIE (posteriormente Comité de seguimiento del Acuerdo de Asociación y de sus evaluaciones), Comité de Evaluación (de FEDER y FESE), Comités de Seguimiento de los programas regionales, Red de Comunicación GERIP (Grupo Español de Responsables en materia de Información y Publicidad, del estado y las CC.AA.), y Redes temáticas. 
Tabla 7. Resumen de los principales resultados esperados por objetivo ${ }^{6}$.

\begin{tabular}{|c|c|c|c|c|}
\hline \multirow{2}{*}{\multicolumn{2}{|c|}{$\begin{array}{l}\text { Fondos } \\
\text { EIE*, a }^{*}\end{array}$}} & \multicolumn{3}{|l|}{ Resultados esperados } \\
\hline & & Indicador & 2012 & 2020 \\
\hline \multirow{4}{*}{ 它 } & \multirow[t]{4}{*}{1,3} & \multicolumn{3}{|c|}{$\begin{array}{l}\text { R.1. Fortalecer el sistema de } I+D+i \text { y en particular la participación del sector privado, a } \\
\text { través de la transferencia de conocimiento y la innovación empresarial, y en línea con la } \\
\text { Estrategia española de } I+D+i \text { y las estrategias regionales de especialización inteligente. }\end{array}$} \\
\hline & & I.1.1.1. Gasto en I+D en $\%$ del PIB & 1.3 & 2 \\
\hline & & $\begin{array}{l}\text { I.1.1.2. \% del gasto total en I+D financiado por el sector } \\
\text { privado }\end{array}$ & 45.6 & 60 \\
\hline & & $\begin{array}{l}\text { I.1.1.3. \% de empresas que realizan innovaciones tecnológicas } \\
\text { sobre total de empresas activas de } 10 \text { o más asalariados }\end{array}$ & 13.22 & 25 \\
\hline \multirow{8}{*}{ స్ } & \multirow[t]{5}{*}{1,3} & \multicolumn{3}{|c|}{$\begin{array}{l}\text { R.2.1. Mejorar la conectividad digital a través del despliegue de redes y la mejora de la } \\
\text { accesibilidad, uso y calidad TIC }\end{array}$} \\
\hline & & I.2.1.1. \% de la población con cobertura de más de $30 \mathrm{Mbs}$ & $59^{\mathrm{b}}$ & 100 \\
\hline & & I.2.1.2. \% de hogares con acceso de más de $100 \mathrm{Mbs}$ & 0.4 & 50 \\
\hline & & $\begin{array}{l}\text { I.2.1.3. \% de personas** que usan Internet de forma regular (al } \\
\text { menos } 1 \text { vez por semana en los últimos } 3 \text { meses) }\end{array}$ & $66^{\mathrm{b}}$ & $>75^{\mathrm{c}}$ \\
\hline & & I.2.1.4. \% de personas** que nunca han accedido a Internet & $24.4^{\mathrm{b}}$ & $<15^{\mathrm{c}}$ \\
\hline & \multirow[t]{3}{*}{1} & \multicolumn{3}{|c|}{$\begin{array}{l}\text { R.2.2. Desarrollar la economía digital orientada al sector privado y las soluciones } \\
\text { e-administración }\end{array}$} \\
\hline & & I.2.2.1. \% de pymes que realizan ventas online & $12.1^{\mathrm{b}}$ & $>33^{\mathrm{c}}$ \\
\hline & & $\begin{array}{l}\text { I.2.2.2. } \% \% \text { de personas** que usan servicios de e- } \\
\text { administración }\end{array}$ & 44 & $>50^{\mathrm{c}}$ \\
\hline \multirow{6}{*}{$\stackrel{m}{0}$} & \multirow[t]{3}{*}{1} & \multicolumn{3}{|c|}{ R.3.1. Potenciar el espíritu emprendedor y la creación de nuevas empresas } \\
\hline & & I.3.1.1. Población de empresas & $\pm 3 \mathrm{M}$ & $>3 \mathrm{M}$ \\
\hline & & $\begin{array}{l}\text { I.3.1.2. Tasa de supervivencia de empresas en el primer año de } \\
\text { vida }\end{array}$ & $77^{\mathrm{d}}$ & $>77$ \\
\hline & \multirow[t]{3}{*}{$1,3,4$} & \multicolumn{3}{|c|}{$\begin{array}{l}\text { R.3.2. Mejorar la viabilidad y la competitividad de las pyme, a través de su crecimiento, } \\
\text { internacionalización, innovación y acceso a financiación }\end{array}$} \\
\hline & & $\begin{array}{l}\text { I.3.2.1. Población de empresas de más de } 10 \text { asalariados } \\
\text { (DIRCE) }\end{array}$ & $0.13 \mathrm{M}^{\mathrm{b}}$ & $>0.13 \mathrm{M}$ \\
\hline & & I.3.2.2. Número de empresas exportadoras (ICEX) & $38.763^{c}$ & $>38.763$ \\
\hline \multirow{5}{*}{ 蔦 } & \multirow[t]{5}{*}{1,3} & \multicolumn{3}{|c|}{$\begin{array}{l}\text { R.4.1. Aumentar la proporción de energías renovables (ER) en el consumo final de } \\
\text { energía así como en todos los modos del sector transporte (UE2020) }\end{array}$} \\
\hline & & I.4.1.1. $\quad \%$ de ER en el consumo final de energía & $15.1^{\mathrm{e}}$ & 20 \\
\hline & & I.4.1.2. \% de ER en todos los modos del sector del transporte & $5.9^{\mathrm{e}}$ & 10 \\
\hline & & \multicolumn{3}{|l|}{ R.4.2. Aumentar el ahorro y la eficiencia energética (UE2020) } \\
\hline & & I.4.2.1. Ahorro energético & & \\
\hline
\end{tabular}

${ }^{6} *$ Fondos EIE: (1) FEDER; (2) FSE, (3)FEADER, (4) FEMP; ** de 16 a 74 años; ${ }^{\text {a }}$ El FSE financiará operaciones a los OT 1 a 6 a través de operaciones del OT8 (empleo); ${ }^{b}$ Valor inicial de 2013; ' Valor a alcanzar en 2015, y reducirlo para 2020 (Agenda Digital para España); ${ }^{\mathrm{d}}$ Valor inicial de 2010; ${ }^{\mathrm{e}}$ Valor inicial de 2011; ${ }^{\mathrm{f}}$ Reducción del 10\% (2005-2020) de emisiones de GEI en los sectores difusos; ${ }^{\mathrm{g}}$ El FEDER y el FEMP también financiarán operaciones; ${ }^{\mathrm{g}}$ Reducir en 1.4-1.5M el número de personas en situación de riesgo (UE2020); ${ }^{\mathrm{i}}$ El FEDER también financiarán operaciones; ${ }^{j}$ El FEDER y el FEADER también financiarán operaciones 
R.4.3. Reducir las emisiones de gases de efecto invernadero (UE2020)

I.4.3.1. Emisiones de gases de efecto invernadero $126.43^{\circ}$

\begin{tabular}{|c|c|c|c|c|c|}
\hline \multirow{4}{*}{$\stackrel{n}{0}$} & \multirow[t]{2}{*}{1} & \multicolumn{4}{|c|}{$\begin{array}{l}\text { R.5.1. Avanzar en la elaboración e implantación de los planes de adaptación al cambio } \\
\text { climático, así como de actuaciones paliativas y preventivas }\end{array}$} \\
\hline & & I.5.1.1. & $\begin{array}{l}\text { Planes de adaptación al cambio climático y actua- } \\
\text { ciones paliativas y preventivas }\end{array}$ & n.d. & avance \\
\hline & \multirow[t]{2}{*}{3} & \multicolumn{4}{|c|}{ R.5.2. Mejorar los ecosistemas relacionados con la agricultura y silvicultura } \\
\hline & & I.5.2.1. & $\begin{array}{l}\text { Superficie acogida a medidas de carácter medioam- } \\
\text { biental }\end{array}$ & n.d. & $\Delta$ \\
\hline
\end{tabular}

\begin{tabular}{|c|c|c|c|c|}
\hline \multirow[b]{3}{*}{$\frac{0}{0}$} & & \multicolumn{3}{|c|}{$\begin{array}{l}\text { R.6.1. Avanzar en el cumplimiento del acervo medioambiental de la UE en materia de } \\
\text { residuos y gestión del agua }\end{array}$} \\
\hline & 1,3 & I.6.1.1. Cumplimiento de las directivas de residuos y agua & n.d. & avance \\
\hline & 3 & $\begin{array}{l}\text { Incremento de la eficiencia del uso del agua en } \\
\text { agricultura en proyectos beneficiarios de PDR }\end{array}$ & n.d. & avance \\
\hline
\end{tabular}
R.6.2. Avanzar en el logro de los obj. de la política pesquera común y la política marítima integrada

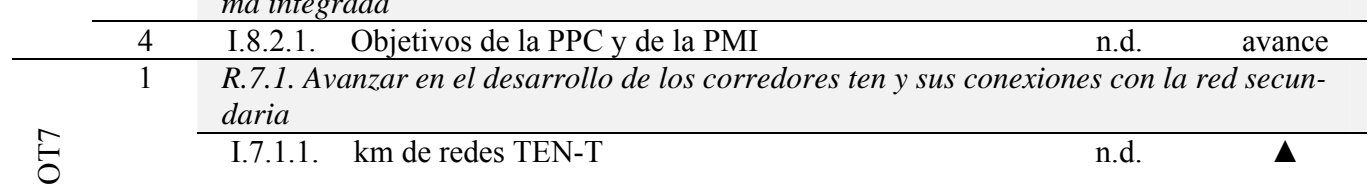

\begin{tabular}{|c|c|c|c|c|}
\hline \multirow{6}{*}{$\stackrel{\infty}{0}$} & \multirow[t]{6}{*}{$2,3^{\mathrm{g}}$} & \multicolumn{3}{|c|}{ R.8.1. Mejorar el empleo así como su calidad, especialmente el empleo de los jóvenes } \\
\hline & & I.8.1.1. Tasa de empleo & 59.3 & 74 \\
\hline & & I.8.1.2. $\quad$ Tasa de desempleo juvenil & 55.7 & $\boldsymbol{\nabla}$ \\
\hline & & \multicolumn{3}{|c|}{ R.8.2. Mejorar en particular el empleo de media y alta cualificación } \\
\hline & & $\begin{array}{l}\text { I.8.2.1. Tasa de desempleo de trabajadores de menor cualifi- } \\
\text { cación }\end{array}$ & 34 & avance \\
\hline & & $\begin{array}{l}\text { I.8.2.2. \% del empleo de media y alta cualificación en el } \\
\text { empleo total }\end{array}$ & 78.97 & $\mathbf{\Delta}$ \\
\hline \multirow{5}{*}{$\stackrel{2}{\circ}$} & \multirow[t]{5}{*}{$2,3^{\mathrm{i}}$} & \multicolumn{3}{|c|}{$\begin{array}{l}\text { R.9.1. Reducir la población en riesgo de pobreza o exclusión social, incl. las zonas } \\
\text { rurales }\end{array}$} \\
\hline & & $\begin{array}{l}\text { I.9.1.1. } \% \text { de personas con riesgo de pobreza o exclusión } \\
\text { social }\end{array}$ & 28.2 & avance $^{\text {h }}$ \\
\hline & & I.9.1.2. $\%$ de hogares con todos los activos parados & $14.11^{\mathrm{b}}$ & $\boldsymbol{\nabla}$ \\
\hline & & \multicolumn{3}{|l|}{ R.9.2. Promover la economía social } \\
\hline & & I.9.2.1. Número de entidades de la economía social (CEPES) & 42684 & avance \\
\hline \multirow{7}{*}{$\begin{array}{l}\text { 음 } \\
\text { ○ }\end{array}$} & $2^{j}$ & \multicolumn{3}{|l|}{ R.10.1. Reducir el abandono escolar prematuro (UE2020) } \\
\hline & & I.10.1.1. Tasa de abandono escolar prematuro & 24.9 & 15 \\
\hline & & $\begin{array}{l}\text { I.10.1.2. \% población }>16 \text { años con educación secundaria } \\
\text { finalizada }\end{array}$ & 23.7 & $\mathbf{\Delta}$ \\
\hline & & \multicolumn{3}{|c|}{$\begin{array}{l}\text { R.10.2. Aumentar la proporción de personas con titulación en enseñanza superior } \\
\text { (UE2020) }\end{array}$} \\
\hline & & I.10.2.1. $\quad$ Tasa de titulación en la enseñanza superior & 40.1 & 44 \\
\hline & & \multicolumn{3}{|c|}{ R.10.3. Mantener y/o aumentar el número de trabajadores en formación continua } \\
\hline & & I.10.3.1. Trabajadores en formación continua & 10.7 & $\mathbf{A}$ \\
\hline
\end{tabular}

Fuente: Elaboración propia. 
Las seis redes temáticas para la coordinación y desarrollo de: la $\mathrm{I}+\mathrm{D}+\mathrm{i}$, igualdad de género, el desarrollo sostenible, el desarrollo urbano sostenible, la inclusión social y el desarrollo rural, responden al principio de coordinación, partenariado y gobernanza multinivel. Las funciones que cumplen son: coordinación en la gestión de los fondos, análisis de la contribución de los fondos, facilitar el intercambio de experiencias y difusión de buenas prácticas, análisis de problemas técnicos, y en general la gestión de los fondos EIE.

Las acciones, y su fecha prevista de ejecución, que se tomarán para garantizar la ejecución eficaz de los Fondos EIE en este periodo de programación, en relación con el FEDER, son la reducción del número de Programas Operativos y de Organismos Intermedios (2014), la elaboración de la aplicación informática de gestión Fondos 2020 (2014-2015), la elaboración de Guías y Manuales de Procedimientos (20142015), la adopción de costes simplificados y flat rates para proyectos generadores de ingresos (2014) y la elaboración de un Plan para la racionalización de las operaciones de Control y Auditoría (2014-2015). En relación con el FSE, reducción del número de participantes (2014), elaboración de la aplicación informática de gestión FSE (2014), elaboración de Guías y Manuales de Procedimientos (2014) y adopción de costes simplificados (ya está en uso). Para mejorar la aplicación del FEADER se continúa trabajando en la automatización del proceso de solicitud, autorización de pagos y verificaciones administrativas, y se revisarán el número de programas y organismos intermedios, y si las regiones asumirían el papel de autoridad de gestión, certificación y/o control.

\subsection{MARCO NACIONAL DE DESARROLLO RURAL}

El Marco Nacional de Desarrollo Rural tiene como objetivo contribuir a la aplicación armonizada de la legislación comunitaria, dando respuesta a intereses comunes, buscando la igualdad de trato en situaciones semejantes, siempre dentro del respeto del marco competencial de las comunidades autónomas y permitiendo la adaptación de sus programas a las especificidades regionales. Se ha establecido un mecanismo para la transferencia de fondos entre programas para una mejor adaptación de las disposiciones financieras al ritmo de ejecución de los programas evitando así la pérdida de fondos comunitarios.

Las medidas para las que se han establecido elementos comunes son: servicios de asesoramiento, agroambiente y clima, agricultura ecológica, zonas con limitaciones naturales y otras limitaciones específicas, medidas forestales, inversiones de mejora de las explotaciones agrarias, inversiones en infraestructuras públicas de riego, inversiones en comercialización y transformación, instalación de jóvenes agricultores, actuaciones de innovación y estrategia LEADER. Las CC.AA. seleccionarán de entre los requisitos obligatorios nacionales aquellos que sean pertinentes para los compromisos de sus PDR, pudiendo incluir otras exigencias mínimas recogidas en su legislación autonómica.

Los pagos de las medidas de agroambiente y clima, agricultura ecológica, ayuda al amparo de la Directiva Marco del Agua, ayuda a favor del bienestar de los animales, 
y ayuda Natura 2000, cubrirán los compromisos que impongan mayores exigencias que los requisitos de la condicionalidad establecidos en el Reglamento 1306/2013. Así también, los PDR regionales deberán imponer mayores exigencias que los requisitos nacionales que sean pertinentes establecidos de acuerdo con el Reglamento $1307 / 2013$.

En el Marco nacional también se establecen medidas para: la exclusión de la doble financiación de prácticas agrícolas y beneficiosas para el clima y el medio ambiente, definir a "agricultor activo" y las "operaciones en explotaciones de ámbito supraautonómico", la delimitación de las operaciones de medidas entre PDR nacional y PDR regionales, definir los umbrales mínimo y máximo de las explotaciones para la concesión de las ayudas, establecer las operaciones de inversión que deben someterse a evaluación de impacto ambiental para poder ser elegibles, determinar los gastos elegibles en las inversiones, para el empleo de instrumentos financieros optativos de carácter nacional, de adhesión voluntaria por parte de las CC.AA., y zonas natura 2000.

Se establecen también las funciones de la Dirección General de Desarrollo Rural y Política Forestal, como Autoridad de coordinación de autoridades de gestión. Entre ellas: la elaboración, modificación y seguimiento del Marco Nacional de Desarrollo Rural junto con su presentación y modificación a la Comisión Europea, la organización y dirección de las actividades del Comité de seguimiento del Marco Nacional, la participación en los Comités de Seguimiento de los PDR regionales, la interlocución con el Fondo Español de Garantía Agraria, con las autoridades nacionales responsables de las actuaciones en desarrollo rural y con la Comisión Europea, la presentación ante la Comisión Europea de los PDR y sus modificaciones, la gestión, difusión y autorización de acceso a la información electrónica, y apoyo a la gestión del FEADER (control, auditorías, aplicación de las disposiciones).

Las medidas establecidas, en conjunto con las CC.AA., en el Marco Nacional de Desarrollo Rural, son:

a) Servicios de asesoramiento, gestión y sustitución de explotaciones agrarias;

b) Agroambiente y clima;

c) Agricultura ecológica,

d) Zonas con limitaciones naturales y otras limitaciones específicas;

e) Medidas forestales;

f) Inversiones de mejora de las explotaciones agrarias,

g) Infraestructuras públicas de regadío

h) Transformación y comercialización de productos agrarios;

i) Instalación de jóvenes agricultores;

j) Innovación;

k) Estrategia LEADER 


\subsection{PROGRAMA NACIONAL DE DESARROLLO RURAL 2014-2020}

El PNDR 2014-2020 se encuentra actualmente en fase inicial, y se presentó a la Comisión Europea el 21 de julio. El periodo de información pública y consultas concluyó el 02 de octubre de 2014. De acuerdo con la normativa europea, el PNDR debe ser coherente y compatible con los PDR regionales, y la delimitación entre ellos se ha establecido en el Marco Nacional. En el PNDR se incluyen las actuaciones de ámbito suprautonómico, de interés general, que serán llevadas a cabo por la Dirección General de Desarrollo Rural y Política Forestal, del MAGRAMA, como responsable de su gestión por parte de la AGE. A continuación se recogen los principales aspectos de esta versión inicial.

Dado el carácter supraregional del PNDR, las necesidades identificadas y prioridades seleccionadas son de ámbito nacional y/o supraautonómico e incluyen aquellas que son competencia de la AGE, así como áreas no cubiertas por los PDR regionales. Además, se dará especial atención a los cuatro retos señalados por la Comisión Europea en el Position Paper para España:

- $\quad$ El incremento de la competitividad de las PYMES y la presencia de las mismas en los mercados internacionales.

- El fortalecimiento del campo de la investigación y la innovación, y la participación del sector privado.

- $\quad$ El fomento del empleo y disminución de la pobreza.

- Un uso eficiente de los recursos naturales.

Basados en la Estrategia Europa 2020, las recomendaciones nacionales, la evaluación ex ante y la Matriz DAFO y necesidades, se definieron las seis prioridades en las que enmarcará el FEADER y los objetivos de desarrollo rural:

- P1. Fomentar la transferencia de conocimientos e innovación en los sectores agrario y forestal y en las zonas rurales.

- P2. Mejorar la viabilidad de las explotaciones agrarias y la competitividad de todos los tipos de agricultura en todas las regiones, y promover las tecnologías agrícolas innovadoras y la gestión forestal sostenible.

- P3. Fomentar la organización de la cadena alimentaria, incluyendo la transformación y comercialización de los productos agrarios, el bienestar animal y la gestión de riesgos en el sector agrario.

- P4. Restaurar, preservar y mejorar los ecosistemas relacionados con la agricultura y la silvicultura.

- P5. Promover la eficiencia de los recursos y fomentar el paso a una economía baja en carbono y capaz de adaptarse al cambio climático en los sectores agrario, alimentario y forestal.

- P6. Fomentar la inclusión social, la reducción de la pobreza y el desarrollo económico en las zonas rurales.

Estas prioridades están en coherencia con el Acuerdo de Asociación y el Marco Nacional, estableciéndose como principales necesidades la innovación en el sector 
agrario y la transferencia de conocimientos en el medio rural (prioridad 1). El mayor número de necesidades identificadas están relacionadas con las prioridades 2 (explotaciones agrarias) y 3 (cadena alimentaria). Además, se ha identificado una necesidad de carácter transversal, la gobernanza institucional, relacionada con el propio funcionamiento del PNDR.

Las líneas estratégicas del PNDR, basadas en las necesidades identificadas para España, han sido establecidas para ayudar en la consecución de los objetivos de la Estrategia Europa 2020 (Figura 10). Como resultado, se deberá trabajar principalmente en la creación y el mantenimiento del empleo estable en el medio rural (principalmente jóvenes y mujeres) a través de la diversificación económica y el fomento y desarrollo de pymes.

Figura 10. Líneas estratégicas y objetivos del PNDR 2014-2020.

Línea 1: Aumentar dimensión e integración de los agentes de las cooperativas y otras entidades asociativas

- OE 1.1: Fomentar integración asociativa agroalimentaria.

-OE 1.2: Fomentar creación de agrupaciones y organizaciones de productores.

- OE 1.3: Favorecer dinamización industrial del sector agroalimentario a través de la cooperación.

Línea 2: Conservación y eficiencia en el uso de los recursos naturales, Iucha contra el cambio climático y fomento del patrimonio rural

- OE 2.1: Mejorar eficiencia de los regadios y favorecer su transformación en zonas prioritarias.

- OE 2.2: Mejorar prevención de incendios forestales y facilitar restauración de danos producidos por grandes incendios.

- $O E$ 2.3: Promover conservación de la biodiversidad a través de recursos genéticos forestales.

-OE 2.4: Promorer puesta en valor del patrimonio natural y cultural a través de consolidar una red de itinerarios naturales para uso no motorizado.

\section{Línea horizontal de innovación}

- OE H.1: Fomentar innoración organizativa

-OE H.2: Promover innovación a través de nuevos productos, procesos y prácticas

Fuente: Elaboración propia.

A estas líneas y objetivos hay que añadir tres objetivos transversales: innovación, medio ambiente $\mathrm{y}$, mitigación del cambio climático y adaptación al mismo. Para articular las líneas estratégicas se han establecidos áreas focales para cada prioridad, y las medidas que se implementarán en cada una de ellas (Tabla 8). Se han considerado nueve medidas de desarrollo rural, con una contribución total del FEADER de 237 $828821.00 €$, y una cofinaciación nacional de $20351850.60 €$ :

- M01.Transferencia de conocimientos y actividades de información (2 $980248.00 €$ ) 
- M02. Servicios de asesoramiento, gestión y sustitución de explotaciones agrarias(9 $934160.00 €)$

- M04. Inversiones en actives físicos (140 398 340.00€)

- M07. Servicios básicos y renovación de poblaciones en las zonas rurales (9 $934163.00 €)+(8809540.77 €)$

- M08. Inversiones en el desarrollo de zonas forestales y mejora de la viabilidad de los bosques (11 $880243.00 €)+(10535309.83 €)$

- M09. Creación de agrupaciones y organizaciones de productores (10 $430870.00 €)$

- M15. Servicios silvoambientales y climáticos y conservación de los bosques (3 $021000.00 €)+(1007000.00 €)$

- M16. Cooperación (39736 644.00€)

- M20. Asistencia técnica Estado miembro $(9,513,153.00 €)$

Conforme lo establecido por la Comisión, se ha destinado el 6\% de la contribución total de la UE a la reserva de eficacia. No se ha dispuesto de financiación nacional adicional para ninguna de las medidas contempladas en el PNDR. Además, se prevé complementar las ayudas de los Fondos EIE con fondos de la PAC, de COSME, de HORIZONTE 2020 y de LIFE. No se han definido subprogramas temáticos en el Programa Nacional de Desarrollo Rural.

Las acciones que se desarrollarán para garantizar la disponibilidad y la capacidad de asesoramiento suficiente, en relación a los requisitos reglamentarios, y la innovación, son:

- Disponibilidad y la capacidad de asesoramiento suficiente

o Asignación de recursos y capacidad organizativa

- Autoridad de Gestión: Dirección General de Desarrollo Rural y Política Forestal

- Comité de Seguimiento del Programa: Compuesto por órganos de la AGE, y Organizaciones sociales, sindicales, industriales, ambientales, etc.

- Comité Ejecutivo de la Red Rural Nacional: con representantes de todos los actores

- Organismo Pagador: Fondo Español de Garantía Agraria (FEGA) MAGRAMA

o Acciones de comunicación a los potenciales beneficiarios de las políticas

- Autoridad de Gestión: responsable de informar a los beneficiarios:

- Oportunidades de financiación

- Evaluación del programa (resultados)

- Red Rural Nacional:

- "Plan de comunicación" con publicidad e información sobre el PDR y actividades de información y comunicación dirigidas a un público amplio

- "Plan de Acción" dirigida a las Actividades relativas a compartir y divulgar las conclusiones del seguimiento y la evaluación 
o Sistema de seguimiento y evaluación para garantizar la recogida y tratamiento adecuado de la información

- Plan de Evaluación

- Autoridad de Gestión: responsable de especificar las medidas para ejecutarlo

- Innovación

o Red Rural Nacional

- Plan de Acción

- Plan de comunicación

En la evaluación de las condicionalidades ex-ante del PNDR se ha establecido que se cumplen las siete condicionalidades generales aplicables a nivel nacional. En relación con las condicionalidades temáticas se cumplen: OT2.2 (Infraestructura de red de próxima generación (RPG), OT4.1 (eficiencia energética), OT4.3 (energía renovable), OT5.1 (prevención de riesgos y gestión de riesgos), OT6.1 (sector del agua).

El "Gasto público total" se ha establecido como indicador aplicable, en el Marco de Rendimiento, para cinco de las seis prioridades (excepto para la prioridad 1):

- P2: Meta 2023 (32 $294057.61 €)$, Hito $2018(21.20 \%)$

- P3: Meta 2023 (301 050 755.46€), Hito 2018 (33.60\%)

- P4: Meta 2023 (31 557 013.00€), Hito 2018 (36.53\%)

- P5: Meta 2023 (27 338 312.39€), Hito 2018 (25.58\%)

- P6: Meta 2023 (18 743 704.00€), Hito 2018 (50.68\%)

Además, se han establecido otros dos indicadores para las prioridades 5 y 6 :

- P5: Tierra agrícola y forestal objeto de gestión para fomentar la captura o conservación de carbono + tierra agrícola objeto de contratos de gestión destinados a reducir las emisiones de GEI y/o de amoníaco + tierra de regadío que pasa a un sistema de riego más eficiente. Meta 2023 (1 992.00), Hito 2018 (33.33\%)

- P6: Número de operaciones subvencionadas para mejorar servicios básicos e infraestructuras en las zonas rurales. Meta 2023 (18), Hito $2018(50.00 \%)$

Finalmente, se han incluido indicadores alternativos, para reemplazar aquellos propuestos por la Comisión Europea que no son de aplicación o no relevantes en España:

- P2: Superficie total transformada en regadío (ha). Meta 2023 (1 328.00), Hito 2018 (33.36\%)

- P3: Número de cooperativas, industrias y organizaciones de productores beneficiarias. Meta 2023 (384.00), Hito 2018 (30.21\%)

- P4: Número de hectáreas en las que se intervendrá con el objetivo principal de prevenir los incendios forestales y su restauración. Meta 2023 (15 000.00), Hito 2018 (41.78\%) 
Tabla 8. Prioridades, áreas focales y medidas del PNDR.

\begin{tabular}{|c|c|c|}
\hline & Áreas focales & Medidas \\
\hline \multirow[t]{3}{*}{ P1 } & $\begin{array}{l}\text { Fomentar la innovación, la cooperación y el desarrollo de la base de conocimientos } \\
\text { en las zonas rurales }\end{array}$ & $\begin{array}{l}\text { M01, M02, } \\
\text { M16 }\end{array}$ \\
\hline & $\begin{array}{l}\text { Reforzar los lazos entre la agricultura, la producción de alimentos y la selvicultura, } \\
\text { por una parte, y la investigación y la innovación, por otra, para, entre otros fines, } \\
\text { conseguir una mejor gestión y mejores resultados medioambientales }\end{array}$ & M16 \\
\hline & $\begin{array}{l}\text { Fomentar el aprendizaje permanente y la formación profesional en el sector agrario } \\
\text { y el sector forestal }\end{array}$ & M01 \\
\hline $\mathrm{P} 2$ & $\begin{array}{l}\text { Mejorar los resultados económicos de todas las explotaciones y facilitar la restruc- } \\
\text { turación y modernización de las mismas, en particular con objeto de incrementar su } \\
\text { participación y orientación hacia el mercado, así como la diversificación agrícola } \\
\text { Facilitar la entrada en el sector agrario de agricultores adecuadamente formados, y } \\
\text { en particular el relevo generacional }\end{array}$ & M04, M16 \\
\hline \multirow[t]{2}{*}{ P3 } & $\begin{array}{l}\text { Mejorar la competitividad de los productores primarios integrándolos en la cadena } \\
\text { agroalimentaria a través de regímenes de calidad, añadir valor a los productos } \\
\text { agrícolas, promoción en mercados locales y en circuitos de distribución cortos, } \\
\text { agrupaciones y organizaciones de productores y organizaciones interprofesionales }\end{array}$ & $\begin{array}{l}\text { M01, M02, } \\
\text { M04, M09, } \\
\quad \text { M16 }\end{array}$ \\
\hline & Apoyar la prevención y la gestión de riesgos en las explotaciones & \\
\hline \multirow[t]{3}{*}{ P4 } & $\begin{array}{l}\text { Restaurar, preservar y mejorar la biodiversidad (incluido en las zonas Natura } 2000 \\
\text { y en las zonas con limitaciones naturales u otras limitaciones específicas), los } \\
\text { sistemas agrarios de alto valor natural, así como el estado de los paisajes europeos }\end{array}$ & $\begin{array}{l}\text { M8, M15, } \\
\text { M16 (SF) }\end{array}$ \\
\hline & $\begin{array}{l}\text { Mejorar la gestión del agua, incluyendo la gestión de los fertilizantes y de los } \\
\text { plaguicidas }\end{array}$ & M16 (SA) \\
\hline & Prevenir la erosión de los suelos y mejorar la gestión de los mismos & \\
\hline \multirow[t]{5}{*}{$\mathrm{P} 5$} & Lograr un uso más eficiente del agua en la agricultura & M04, M16 \\
\hline & $\begin{array}{l}\text { Lograr un uso más eficiente de la energía en la agricultura y en la transformación } \\
\text { de alimentos }\end{array}$ & M16 \\
\hline & $\begin{array}{l}\text { Facilitar el suministro y el uso de fuentes renovables de energía, subproductos, } \\
\text { desechos y residuos y demás materia prima no alimentaria para impulsar el } \\
\text { desarrollo de la bioeconomía }\end{array}$ & M16 \\
\hline & Reducir las emisiones de GEI y de amoníaco procedentes de la agricultura & \\
\hline & Fomentar la conservación y captura de carbono en los sectores agrícola y forestal & \\
\hline \multirow[t]{3}{*}{ P6 } & $\begin{array}{l}\text { Facilitar la diversificación, la creación y el desarrollo de pequeñas empresas y la } \\
\text { creación de empleo }\end{array}$ & \\
\hline & Promover el desarrollo local en las zonas rurales & M07 \\
\hline & $\begin{array}{l}\text { Mejorar la accesibilidad a las TIC así como el uso y la calidad de ellas en las zonas } \\
\text { rurales }\end{array}$ & \\
\hline
\end{tabular}

SA - Medidas para superficies agrícolas

SF - Medidas para superficies forestales

Fuente: Elaboración propia.

La Red Rural Nacional (RRN) integrará a las organizaciones y administraciones participantes en el desarrollo rural. Su principal herramienta de dirección y coordinación será una plataforma web. Su Plan de Acción contempla: 
- Aumentar la participación de las partes interesadas en la aplicación de los programas de desarrollo rural

- Mejorar la calidad de la aplicación de los programas de desarrollo rural.

- Informar al público en general y a los beneficiarios potenciales sobre la política de desarrollo rural y las posibilidades de financiación

- Potenciar la innovación en el sector agrícola, la producción alimentaria, la selvicultura y las zonas rurales.

- Potenciar la colaboración para la realización de proyectos innovadores y facilitar la transferencia de los resultados de los mismos en el marco de la AEI.

Para las acciones a desarrollar se ha establecido un sistema de indicadores (indicadores de impacto - objetivos globales, de resultado - indicadores específicos y ouputs - actividades) que permitirá su seguimiento y evaluación. El monto total para financiar a la RRN es de $15094340 €$, de los cuales el FEADER aportará $8000000 €$.

\section{CONSIDERACIONES FINALES}

En resumen, la política de Desarrollo Rural 2014-2020, a través de las decisiones y reglamentos que la regulan, se caracteriza porque existe un mayor acercamiento entre la política de desarrollo rural y la de cohesión territorial mediante la vinculación con la Estrategia Europa 2020 y las políticas sectoriales. En el marco de esta vinculación, se han establecido objetivos claros y medibles mediante indicadores de resultados, que permitan un seguimiento y una evaluación más eficaz, para un mejor control de la inversión realizada. Además, el reglamento común para los fondos EIE permitirá un trabajo coordinado entre ellos, con el objetivo de alcanzar una mayor efectividad en el uso de los recursos. En este caso, el uso de recursos de uno o más fondos en distintas medidas y operaciones, es una mejora en relación con el periodo 2007-2013.

Destaca el fuerte carácter medioambiental de las medidas y operaciones a ejecutar, en coherencia con los objetivos de la Estrategia Europa 2020. También, la asignación de recursos a sectores con perspectivas de crecimiento importante, y de carácter innovador; la aplicación del enfoque integrado del desarrollo territorial, y un mayor incentivo de las medidas destinadas a jóvenes, mujeres y grupos minoritarios.

La innovación en todos los ámbitos del mundo rural es una apuesta importante de la UE para este nuevo periodo de programación. No solo a través del aumento del presupuesto para este ámbito, sino también por la búsqueda de una mejor articulación y coordinación entre las políticas sectoriales y las de $\mathrm{I}+\mathrm{D}+\mathrm{i}$, y de una mejor difusión de los avances y conocimientos generados.

En relación con la gobernanza, la simplificación de los aspectos administrativos y la participación de los socios en todas las fases del PDR constituyen un avance en la gestión y empoderamiento de los proyectos. Para Tiana (2013), el mayor vínculo entre la política de cohesión y la gobernanza económica que se establece en la gestión de los Fondos EIE puede significar que los Estados miembros que no cumplan con las 
medidas macroeconómicas establecidas por los organismos europeos, puedan ver suspendidos los pagos de los fondos EIE, teniendo efectos negativos en los beneficiarios finales del desarrollo rural.

LEADER sigue siendo el pilar de las ayudas del FEADER y de desarrollo rural en general, adquiriendo en este nuevo periodo de programación un enfoque más abierto al gestionar las ayudas de otros fondos europeos. Éste nuevo enfoque busca armonizar las distintas ayudas destinadas al sector rural, así como también focalizar los recursos en estrategias coordinadas e integradas de carácter multisectorial (desarrollo territorial integrado).

\section{BIBLIOGRAFÍA}

1 ARROYOS, C. (2007). Desarrollo Rural Sostenible en la UE, El nuevo FEADER 2007-2013. Ediciones Mundi-Prensa. Madrid.

2 CAZORLA, A. (1994). Experiencias de desarrollo rural en una iniciativa LEADER. Dirección General de Agricultura y Alimentación. Madrid, España.

3 COMISIÓN EUROPEA. (1999). Reglamento (CE) núm. 1257/1999, de 17 de mayo de 1999 sobre la ayuda al desarrollo rural a cargo del Fondo Europeo de Orientación y de Garantía Agrícola (FEOGA) por el que se modifican y derogan determinados Reglamentos.

4 COMISIÓN EUROPEA. (1999). Reglamento (CE) núm. 1260/1999, de 21 de junio de 1999 por el que se establecen disposiciones generales sobre los Fondos Estructurales

5 COMISIÓN EUROPEA. (2005). Reglamento (CE) núm. 1698/2005, del Consejo de 20 de septiembre de 2005 relativo a la ayuda al desarrollo rural a través del Fondo Europeo Agrícola de Desarrollo Rural (FEADER).

6 COMISIÓN EUROPEA. (2013). Reglamento (UE) núm.1299/2013 del Parlamento Europeo y del Consejo de 17 de diciembre de 2013 por el que se establecen disposiciones específicas relativas al apoyo del Fondo Europeo de Desarrollo Regional al objetivo de cooperación territorial europea.

7 COMISIÓN EUROPEA. (2013). Reglamento (UE) núm.1301/2013 del Parlamento Europeo y del Consejo de 17 de diciembre de 2013 sobre el Fondo Europeo de Desarrollo Regional y sobre disposiciones específicas relativas al objetivo de inversión en crecimiento y empleo y por el que se deroga el Reglamento (CE) núm. 1080/2006

8 COMISIÓN EUROPEA. (2013). Reglamento (UE) núm. 1303/2013, del Parlamento Europeo y del Consejo de 17 de diciembre de 2013 por el que se establecen disposiciones comunes relativas al Fondo Europeo de Desarrollo Regional, al Fondo Social Europeo, al Fondo de Cohesión, al Fondo Europeo Agrícola de Desarrollo Rural y al Fondo Europeo Marítimo y de la Pesca, y por el que se establecen disposiciones generales relativas al Fondo Europeo de Desarrollo Regional, al Fondo Social Europeo, al Fondo de Cohesión y al Fondo Europeo Marítimo y de la Pesca, y se deroga el Reglamento (CE) núm. 1083/2006 del Consejo. 
9 COMISIÓN EUROPEA. (2013). Reglamento (UE) núm. 1304/2013, del Parlamento Europeo y del Consejo de 17 de diciembre de 2013 relativo al Fondo Social Europeo y por el que se deroga el Reglamento (CE) núm. 1081/2006 del Consejo.

10 COMISIÓN EUROPEA. (2013). Reglamento (UE) núm. 1305/2013, del Parlamento Europeo y del Consejo de 17 de diciembre de 2013 relativo a la ayuda al desarrollo rural a través del Fondo Europeo Agrícola de Desarrollo Rural, que establece las medidas de desarrollo rural a financiar por este fondo para el período 2014-2020.

11 COORDINADORA DE ORGANIZACIONES DE AGRICULTORES Y GANADEROS (COAG). (2006). Política de Desarrollo Rural 2007-2013 - Una oportunidad para la agricultura sostenible. Coordinadora de Organizaciones de Agricultores y Ganaderos. Madrid.

12 COMUNIDADES EUROPEAS. (2006). Política de Desarrollo Rural de la UE 2007-2013. Oficina de Publicaciones. Luxemburgo.

13 DE PABLO, et al. (2006). Política de desarrollo rural en países desarrollados versus países en desarrollo. Universidad de Almería. España.

14 FAO. (2003). La nueva ruralidad en Europa y su interés para América Latina.

15 FODEPAL. (2006). Desarrollo rural: Nuevos enfoques y métodos.

16 GALLARDO, R. (2013). Claves para entender el nuevo Marco Estratégico Común. La reforma de las políticas europeas de desarrollo y cohesion territorial. Córdoba, 24 de abril de 2013.

17 MARTÍNEZ ARROYO, F. (2006). El desarrollo rural en el contexto de la Unión Europea. Norba. Revista de Geografía. XI. p. 11-20.

18 MINISTERIO DE AGRICULTURA, ALIMENTACIÓN Y MEDIO AMBIENTE (MAGRAMA). (2014). Borrador de Marco Nacional de Desarrollo Rural 20142020. Ministerio de Agricultura, Alimentación y Medio Ambiente. Direccion General de Desarrollo Rural y Politica Forestal. España.

19 MINISTERIO DE AGRICULTURA, ALIMENTACIÓN Y MEDIO AMBIENTE (MAGRAMA). (2014). Versión inicial del Programa Nacional de Desarrollo Rural 2014-2020. Ministerio de Agricultura, Alimentación y Medio Ambiente.

20 MINISTERIO DE AGRICULTURA, PESCA Y ALIMENTACIÓN (MAPA). (2007). Marco Nacional de desarrollo rural 2007-2013. Ministerio de Agricultura, Pesca y Alimentación. España.

21 MINISTERIO DE HACIENDA Y ADMINISTRACIONES PÚBLICAS. (2014). Acuerdo de Asociación de España 2014-2020.19 Ministerio de Hacienda y Administraciones Públicas. España.

22 PALVIAINEN, S. (2006). Spatial planning and rural development - Good practices, better policies. BIRD project. University of Joensuu. Finland.

23 TIANA CASABLANCAS, X. (2013). La política de cohesión de la Unión Europea 2014-2020: Oportunidades para los gobiernos locales en un contexto de dificultad. $\mathrm{P}^{3} \mathrm{~T}$, Journal of Public Policies and Territories. 4. p. 16-24. 